\title{
Imaging With the Past: Revealing the Complexity of Chimaeroid Pelvic Musculature Anatomy and Development
}

\author{
Jacob B. Pears ${ }^{1,2}$, Carley Tillett ${ }^{3}$, Rui Tahara ${ }^{4}$, Hans C. E. Larsson ${ }^{4}$ and \\ Catherine A. Boisvert ${ }^{1,2 *}$
}

${ }^{1}$ School of Molecular and Life Sciences, Curtin University, Perth, WA, Australia, ${ }^{2}$ Curtin Health Innovation Research Institute, Curtin University, Perth, WA, Australia, ${ }^{3}$ Hub for Immersive Visualization and eResearch, Curtin University, Perth WA, Australia, ${ }^{4}$ Redpath Museum, McGill University, Montreal, QC, Canada

\section{OPEN ACCESS}

Edited by: David Ellard Keith Ferrier, University of St Andrews, United Kingdom

Reviewed by:

Katharine Criswell, University of Cambridge, United Kingdom

Richard Dearden,

Muséum National d'Histoire Naturelle,

France

*Correspondence:

Catherine A. Boisvert

Catherine.Boisvert@curtin.edu.au

Specialty section:

This article was submitted to Evolutionary Developmental Biology, a section of the journal

Frontiers in Ecology and Evolution

Received: 10 November 2021 Accepted: 17 December 2021

Published: 09 February 2022

Citation:

Pears JB, Tillett C, Tahara R, Larsson HCE and Boisvert CA (2022)

Imaging With the Past: Revealing the Complexity of Chimaeroid Pelvic

Musculature Anatomy and Development.

Front. Ecol. Evol. 9:812561. doi: 10.3389/fevo.2021.812561
Chondrichthyans are now widely adopted as models for examining the development and evolution of the stem gnathostome body plan. The fins of some cartilaginous fish are recognized for their plesiomorphic form and mode of muscular development, i.e., epithelial extension. Despite detailed molecular and descriptive examinations of these developmental mechanisms, there has been little contemporary examination of the ontogeny and morphology of the musculature in chondrichthyans including that of the paired fins. This gap represents a need for further examination of the developmental morphology of these appendicular musculatures to gain insight into their evolution in gnathostomes. The elephant shark is a Holocephalan, the sister group of all other chondrichthyans (Holocephali: Callorhinchus milii). Here, we use nano-CT imaging and 3D reconstructions to describe the development of the pelvic musculature of a growth series of elephant shark embryos. We also use historical descriptions from the nineteenth century and traditional dissection methods to describe the adult anatomy. This combined approach, using traditional methods and historical knowledge with modern imaging techniques, has enabled a more thorough examination of the anatomy and development of the pelvic musculature revealing that chimaeroid musculatures are more complex than previously thought. These data, when compared to extant and extinct sister taxa, are essential for interpreting and reconstructing fossil musculatures as well as understanding the evolution of paired fins.

Keywords: chimaeroid, muscle development, nano-CT, elephant shark, appendicular muscles, pelvic anatomy, clasper

\section{INTRODUCTION}

Comparative anatomy has been essential in the study of the evolution of paired fins. By comparing the anatomy and development of sister taxa at phylogenetically significant intervals, researchers have been able to distinguish plesiomorphic and derived traits to better understand how fins have evolved in the gnathostome clade (Neyt et al., 2000; Tanaka et al., 2002; Cole and Currie, 2007; Cole et al., 2011; Wilhelm et al., 2015; Ziermann et al., 2017). In these analyses, cartilaginous fish (Chondrichthyes) are often assumed to represent the pleisomorphic condition relative to osteichthyans. This dates back to the comparative anatomists of the late nineteenth century (Balfour, 1878, 1881), who used chondrichthyans as the best extant models for the "primitive" 
condition of the jawed vertebrate body plan (Cole and Currie, 2007; Coolen et al., 2008; Brazeau and Friedman, 2015; Larouche et al., 2017). Although chondrichtyans do retain pleisomorphic characteristics, some, like the presence of mineralized cartilage, are autapomorphies. On their own, they do not represent the "primitive bauplan" of jawed vertebrates but present phylogenetically important anatomies. In order to understand the origin and evolution of paired fins, their anatomy must be compared to that of other extant and extinct sister taxa.

In recent years, comparative anatomy, specifically examinations of the musculature, has been used, by a vocal minority, to challenge the long held view that pectoral and pelvic fins are serial homologs (Diogo and Molnar, 2014; Diogo and Ziermann, 2015; Ziermann et al., 2017; Diogo, 2020; Siomava et al., 2020). Among these studies, only a single paper (Ziermann et al., 2017) has looked at fin muscle development despite its essential role in addressing questions such as the validity of serial homology (Ziermann et al., 2017). Current studies of chondrichthyan muscle development are sparse, with the majority of the research having been conducted in the late nineteenth (Balfour, 1878, 1881; Dohrn, 1884; Mollier, 1892; Braus, 1899) and early twentieth centuries (Goodrich, 1906; Edgeworth, 1911, 1935). Contemporary research has focused on the developmental mechanisms of fins (Neyt et al., 2000; Tanaka et al., 2002; Cole and Currie, 2007; Cole et al., 2011; Freitas et al., 2014) with the exception of Ziermann et al. (2017), which does describe the development of specific muscles across ontogeny as opposed to solely examining the mechanisms of appendicular muscle development. The historical literature has also examined an array of different elasmobranch taxa, including members of the Squaliformes (Braus, 1898, 1899), Carcharhiniformes (Balfour, 1878; Dohrn, 1884; Mollier, 1892; Goodrich, 1906), and Torpediniformes (Dohrn, 1884; Mollier, 1892; Braus, 1899). While this body of work is vast, detailed and almost exclusively in German, it is also generally limited to observations of the mesodermal cells that form the fin muscles and their early development, with no description of the development of specific muscles. This scarcity of developmental data indicate a need for more detailed morphological descriptions of the ontogeny of the musculature in cartilaginous fish to better address currently debated homology questions.

Holocephalans are the sister group of all other chondricthyans (Sharks, skates, and rays) (Ehrlich, 2010; Inoue et al., 2010; Maisey, 2012; Venkatesh et al., 2014) and have been used as models for examining gnathostome vertebrate morphology and development (Trinajstic et al., 2013, 2018), including the development of the musculature of paired fins (Cole et al., 2011). In contrast with elasmobranchs, selachians in particular, the appendicular muscles of holocephalans have not been described in an array of different species. As far as we are aware, there is only one contemporary description of chimaeroid pelvic fin muscle anatomy, that of the ratfish (Hydrolagus colliei) (Diogo and Ziermann, 2015), and one in the historical literature of the rabbit fish (Chimaera monstrosa) (Davidoff, 1879). Further, only two descriptions of the pelvic clasper musculature of C. monstrosa and Callorhynchus antarcticus (sic) are present in the historical literature (Davidoff, 1879; Jungersen, 1899). To date there has been no study describing the morphology of these muscles across ontogeny.

Callorhinchid chimaeras such as the elephant shark (Callorhinchus milii) are the sister group to all living holocephalans (Inoue et al., 2010; Cole et al., 2011; Venkatesh et al., 2014) and therefore represent a unique model to examine gnathostome development. Here, we have examined the development and morphology of the pelvic musculature of C. milii via nano Computed Tomography (CT) imaging and anatomical dissection. In contrast with traditional methods, this nano-CT imaging allows for the non-destructive visualization of the anatomy in fine detail in situ, which can be reproduced in $3 \mathrm{D}$ models of the pelvic skeleton and musculature. Further, we compare our description of adult morphology with those of other chimaeroids in the historical and contemporary literature to determine any muscle homologies. Through these analyses, we aim to address the lack of developmental and anatomical data and better inform current understandings and hypotheses on the evolution and nature of the vertebrate fin skeleton.

\section{MATERIALS AND METHODS}

\section{Adult and Embryonic Materials}

To source the embryonic growth series, multiple adult female Callorhinchus milii were caught by rod and reel from Western Port bay, Victoria, Australia (License Numbers: DPR RP1000, RP1003, and RP1112). These individuals were transported, housed and kept according to established practice (Boisvert et al., 2015) until eggs were laid, after which they were released in the wild. Eggs were raised in a closed system aquarium (Boisvert et al., 2015) and euthanized at different stages of development using Tricaine. Specimens were staged according to their length and external morphology as per Didier et al. (1998). Where it could be determined by external morphology, male embryonic specimens were selected to enable the description of the developing claspers. Specimens were then fixed in $4 \%$ paraformaldehyde (PFA) in phosphate buffer solution (PBS) and dehydrated in ethanol or methanol. All procedures were conducted following the directions and authorization of the Monash University Animal Ethics Committee (Permit: MAS/ARMI/2010/01).

Adult specimens were also caught by rod and reel from Western Port bay, Victoria, Australia (License Numbers: DPR RP RP1000, RP1003, and RP1112). Individuals were transported and housed by the same practices, but died in captivity and were used for dissections. All procedures were conducted following the directions and authorization of the Monash University Animal Ethics Committee (Permit: MAS/ARMI/2010/01).

\section{Nano Computed Tomography Imaging}

To examine muscular development across ontogeny in a nondestructive manner, a growth series (stages 30, 32, and 34; Didier et al., 1998) of elephant shark (Callorhinchus milii) embryos were stained using 1\% phosphotungstic acid (PTA) (1\% PTA dissolved in $70 \% \mathrm{EtOH}$ ). Embryos were quickly washed with $70 \% \mathrm{EtOH}$ to remove excessive stain on the surface, and then nano-CT scanned in $0.5 \%$ agarose on a Zeiss Xradia 520 Versa (Carl Zeiss Canada 
Ltd., ON, Canada) at McGill University. The staining duration and imaging parameters for each stage are given in Table $\mathbf{1 .}$

\section{D Modeling}

Nano-CT data was reconstructed using Reconstructor (Carl Zeiss Canada Ltd., ON, Canada) and 3D models of the pelvic muscles were visualized using Dragonfly version 2020.1 (Object Research Systems) ${ }^{1}$.

\section{Dissection and Gross Anatomy}

Adult male and female C. milii were dissected with scalpel and forceps to examine the gross anatomy of the pelvic musculature. They were photographed with a Canon digital camera.

\section{Nomenclature}

There are currently two known descriptions of holocephalan pelvic musculatures: rabbit fish (Chimaera monstrosa) (Davidoff, 1879) and the spotted ratfish (Hydrolagus colliei) (Diogo and Ziermann, 2015). Our description of the pelvic musculature of C. milii is more similar to that of C. monstrosa than H. colliei. We have therefore translated the terminology of C. monstrosa from German into English, to use for the present study, but, in

${ }^{1}$ https://www.theobjects.com/dragonfly/new.html cases where this terminology did not include structures found in C. milii, that of H. colliei was used (Tables 2-4).

There are three descriptions of pelvic clasper musculature in chimaeroids, those of C. monstrosa and Callorhynchus antarcticus (Jungersen, 1899) and another of C. monstrosa (Davidoff, 1879). In our description of the muscles of the pelvic claspers of C. milii, we have adapted the terminology of Davidoff (1879) as applied by Jungersen (1899) to describe C. antarcticus as this is from the same genus and is very similar in morphology to C. milii (Table 5). Another muscle associated with the prepelvic tenaculum was observed in C. monstrosa (Davidoff, 1879) and C. antarcticus (Parker, 1886), however, remained unnamed (Table 6). We propose a new name for this muscle (see below).

\section{RESULTS}

\section{Adult Pelvic Musculature Dorsal Musculature}

The dorsal musculature consists of the portio prima, portio tertia, portio secunda, and deep dorsal layer. The dorsal half of the iliac ramus of the pelvic girdle is situated atop the hypaxial musculature, ranging from the midline to the middle of the hypaxial musculature at a $45^{\circ}$ angle. The pelvic girdle is covered

TABLE 1 | Staining duration and imaging parameters of embryonic specimens.

\begin{tabular}{|c|c|c|c|c|c|c|}
\hline Stage & Staining (days) & Voltage (kV) & Power (W) & Exp. time (sec) & Scan time (h) & Voxel size $(\mu \mathrm{m})$ \\
\hline 30 & 27 & 60 & 5 & 3.0 & 5.0 & 3.0 \\
\hline 32 & 67 & 60 & 5 & 4.5 & 6.5 & 4.0 \\
\hline 34 & 69 & 60 & 5 & 5.0 & 7.0 & 5.5 \\
\hline
\end{tabular}

TABLE 2 | Chimaeroid dorsal pelvic musculature and their points of origin (O) and insertion (I).

\begin{tabular}{|c|c|c|c|c|}
\hline Muscle & $\begin{array}{l}\text { Chimaera monstrosa (Davidoff, } \\
\text { 1879) }\end{array}$ & Callorhinchus milii (This study) & Muscle & $\begin{array}{l}\text { Hydrolagus colliei (Diogo } \\
\text { and Ziermann, 2015) }\end{array}$ \\
\hline Portio prima & $\begin{array}{l}\text { O: External aponeurosis } \\
\text { I: Front fin secondary skeleton } \\
\text { (Ceratotrichia) }\end{array}$ & $\begin{array}{l}\text { O: Body muscle fascia and lliac ramus } \\
\text { I: Ceratotrichia and Deep dorsal layer }\end{array}$ & Adductor superficialis & $\begin{array}{l}\text { O: Body muscle fascia } \\
\text { I: Dorsal radial cartilage }\end{array}$ \\
\hline Portio tertia & $\begin{array}{l}\text { O: llium } \\
\text { I: Deep dorsal layer }\end{array}$ & $\begin{array}{l}\text { O: lliac ramus } \\
\text { I: Deep dorsal layer }\end{array}$ & Not described & \\
\hline Portio secunda & $\begin{array}{l}\text { O: External aponeurosis and llium } \\
\text { I: Second fin metapterygium (o)/Basal } \\
\text { appendage }\left(\sigma^{\top}\right)\end{array}$ & $\begin{array}{l}\text { O: Fascia of the body muscle, pelvic } \\
\text { girdle and cloaca } \\
\text { I: Second fin metapterygium (o)/Anterior } \\
\text { clasper cartilage }\left(0^{\top}\right)\end{array}$ & Levator 5 & $\begin{array}{l}\text { O: Body muscle fascia } \\
\text { I: Basipterygium and Medial } \\
\text { radial cartilages }\end{array}$ \\
\hline $\begin{array}{l}\text { Deep dorsal layer } \\
\text { (tiefe dorsale }\end{array}$ & $\begin{array}{l}\text { O: Dorsal surface of basipterygium } \\
\text { I: Radial muscles }\end{array}$ & $\begin{array}{l}\text { O: Dorsal surface of basipterygium } \\
\text { I: Dorsal radial cartilage }\end{array}$ & Adductor (Deep bundle) & $\begin{array}{l}\text { O:Basipterygium } \\
\text { I: Dorsal Radial Cartilage }\end{array}$ \\
\hline
\end{tabular}

Schicht)

TABLE 3 | Chimaeroid lateral pelvic musculature and their points of origin $(\mathrm{O})$ and insertion (I).

\begin{tabular}{|c|c|c|c|c|}
\hline Muscle & $\begin{array}{l}\text { Chimaera monstrosa } \\
\text { (Davidoff, 1879) }\end{array}$ & Callorhinchus milii (This study) & Muscle & $\begin{array}{l}\text { Hydrolagus colliei (Diogo } \\
\text { and Ziermann, 2015) }\end{array}$ \\
\hline Protractor & $\begin{array}{l}\text { Not described } \\
\text { (But see Lateral } \\
\text { musculature) }\end{array}$ & $\begin{array}{l}\text { O: Body muscle fascia and Pelvic } \\
\text { girdle } \\
\text { I: Basipterygial process }\end{array}$ & Protractor & $\begin{array}{l}\text { O: Pelvic girdle } \\
\text { I: Propterygium }\end{array}$ \\
\hline Abdominal adductor & Not described & $\begin{array}{l}\text { O: Body muscle fascia } \\
\text { I: Pelvic girdle }\end{array}$ & Not described & \\
\hline
\end{tabular}


TABLE 4 | Chimaeroid ventral pelvic musculature and their points of origin $(\mathrm{O})$ and insertion (I).

\begin{tabular}{|c|c|c|c|c|}
\hline Muscle & $\begin{array}{l}\text { Chimaera monstrosa (Davidoff, } \\
\text { 1879) }\end{array}$ & Callorhinchus milii (This study) & Muscle & $\begin{array}{l}\text { Hydrolagus colliei (Diogo } \\
\text { and Ziermann, 2015) }\end{array}$ \\
\hline $\begin{array}{l}\text { Basio-radial layer } \\
\text { (Basio-radiale } \\
\text { Schicht) }\end{array}$ & $\begin{array}{l}\text { O: Ventral surface of basipterygium } \\
\text { I: Ventral radial cartilage }\end{array}$ & $\begin{array}{l}\text { O: Ventral surface of basipterygium } \\
\text { I: Ventral radial cartilages }\end{array}$ & Abductor distalis & $\begin{array}{l}\text { O: Basipterygium } \\
\text { I: Ventral radial cartilage }\end{array}$ \\
\hline $\begin{array}{l}\text { Superficial ventral } \\
\text { layer (oberflächliche } \\
\text { ventrale Schicht) }\end{array}$ & $\begin{array}{l}\text { O: Aponeurotic band and Ventral } \\
\text { surface of ventral pelvic segment } \\
\text { l: Anterior portion of basio-radial } \\
\text { layer }\end{array}$ & $\begin{array}{l}\text { O: Ventral surface of pelvic girdle } \\
\text { I:Ceratotrichia and Anterior portion } \\
\text { of basio-radial layer }\end{array}$ & Abductor proximalis & $\begin{array}{l}\text { O: Puboischiac bar } \\
\text { I: Basipterygium }\end{array}$ \\
\hline Proximal radial layer & Not described & $\begin{array}{l}\text { O: Proximal edge of the } \\
\text { basipterygium and second fin } \\
\text { metapterygium (o)/Anterior clasper } \\
\text { cartilage }\left(\sigma^{\top}\right) \\
\text { I: Proximal fin radials }\end{array}$ & Not described & \\
\hline
\end{tabular}

TABLE 5 | Chimaeroid clasper musculature and their points of origin $(\mathrm{O})$ and insertion (I).

\begin{tabular}{|c|c|c|c|c|c|c|c|}
\hline \multirow{2}{*}{$\begin{array}{l}\text { Muscle } \\
\text { Adductor }\end{array}$} & \multirow{2}{*}{$\begin{array}{l}\text { Chimaera monstrosa } \\
\text { (Jungersen, 1899) } \\
\text { O: Ventral surface of } \\
\text { pelvic girdle and } \\
\text { inter-pelvic band } \\
\text { I: b1 cartilage }\end{array}$} & \multicolumn{2}{|c|}{$\begin{array}{c}\text { Chimaera monstrosa } \\
\text { (Davidoff, 1879) }\end{array}$} & \multicolumn{2}{|c|}{$\begin{array}{c}\text { Callorhynchus antarcticus } \\
\text { (Jungersen, 1899) }\end{array}$} & \multicolumn{2}{|c|}{$\begin{array}{l}\text { Callorhinchus milii } \\
\text { (This study) }\end{array}$} \\
\hline & & Adductor & $\begin{array}{l}\text { O: Medial surface 1st and } \\
\text { 2nd cartilages } \\
\text { I: Medial surface ventral } \\
\text { process }\end{array}$ & $\begin{array}{l}\text { Dilatator (sic) } \\
\text { dorsal portion }\end{array}$ & $\begin{array}{l}\text { O: b1 cartilage (anterior } \\
\text { clasper cartilage } \\
\text { I: Appendix-stem } \\
\text { (Posterior clasper } \\
\text { cartilage) }\end{array}$ & Adductor & $\begin{array}{l}\text { O: Dorsal surface of } \\
\text { the pelvic girdle } \\
\text { cartilage } \\
\text { I: Posterior clasper } \\
\text { cartilage }\end{array}$ \\
\hline Dilatator (sic) & $\begin{array}{l}\text { O: Hinder end of basale } \\
\text { and b1 cartilage } \\
\text { I: Anterior part of b1 } \\
\text { cartilage }\end{array}$ & Flexor & $\begin{array}{l}\text { O: Basal metapterygii } \\
\text { I: Ventral process of clasper } \\
\text { cartilage }\end{array}$ & $\begin{array}{l}\text { Dilatator (sic) } \\
\text { ventral portion }\end{array}$ & $\begin{array}{l}\text { O: Basale } \\
\text { I: Appendix-stem } \\
\text { (Posterior clasper } \\
\text { cartilage) }\end{array}$ & Flexor & $\begin{array}{l}\text { O: Base of } \\
\text { basipterygium } \\
\text { I: Posterior clasper } \\
\text { cartilage }\end{array}$ \\
\hline Compressor & $\begin{array}{l}\text { O: Lateral edge of } \beta \\
\text { cartilage } \\
\text { I: Lateral surface b1 } \\
\text { cartilage and appendix- } \\
\text { stem }\end{array}$ & Abductor & $\begin{array}{l}\text { O: Lateral edge of 3rd } \\
\text { cartilage } \\
\text { I: Ventral process }\end{array}$ & Compressor & $\begin{array}{l}\text { O: Lateral edge of b1 } \\
\text { cartilage } \\
\text { I: Appendix-stem } \\
\text { (Posterior clasper } \\
\text { cartilage) }\end{array}$ & Abductor & $\begin{array}{l}\text { O: Anterior clasper } \\
\text { cartilage } \\
\text { I: Posterior clasper } \\
\text { cartilage }\end{array}$ \\
\hline $\begin{array}{l}\text { Pelvico-basal } \\
\text { layer (pelvico- } \\
\text { basale } \\
\text { Schicht) }\end{array}$ & $\begin{array}{l}\text { O: Dorsal surface of the } \\
\text { pelvis and Tendinous } \\
\text { pelvic band } \\
\text { I: Medial edge of basal, } \\
\text { b1 and process }\left(\sigma^{\top}\right)\end{array}$ & \multicolumn{2}{|c|}{$\begin{array}{l}\text { O: Dorsal surface of } \\
\text { ventral pelvic segment } \\
\text { I: Basipterygium } \\
\text { (ф)/Basal appendage } \\
\text { process }\left(\sigma^{\top}\right)\end{array}$} & Not described & & \multicolumn{2}{|c|}{$\begin{array}{l}\text { O: Dorsal surface of } \\
\text { ventral pelvic segment } \\
\text { I: Second fin } \\
\text { metapterygium } \\
(\text { o) } / \text { Anterior clasper } \\
\text { cartilage }\left(\sigma^{\top}\right)\end{array}$} \\
\hline
\end{tabular}

TABLE 6 | Points of origin (O) and insertion (I) of the muscle associated with the pre-pelvic tenaculum.

\begin{tabular}{|c|c|c|c|c|c|}
\hline \multicolumn{2}{|c|}{ Chimaera monstrosa (Davidoff, 1879) } & \multicolumn{2}{|c|}{ Callorhynchus antarcticus (Parker, 1886) } & \multicolumn{2}{|c|}{ Callorhinchus milii (This study) } \\
\hline $\begin{array}{l}\text { Saw plate } \\
\text { (Sägeblatt) } \\
\text { muscle }\end{array}$ & $\begin{array}{l}\text { O: Dorsal surface of pelvic } \\
\text { girdle } \\
\text { I: Saw plate (Tenaculum) }\end{array}$ & Strong muscle & $\begin{array}{l}\text { O: Inner surface of pelvic } \\
\text { cartilage } \\
\text { I: Anterior clasper (Tenaculum) }\end{array}$ & $\begin{array}{l}\text { Tenaculum } \\
\text { muscle }\end{array}$ & $\begin{array}{l}\text { O: Dorsal surface of pelvic } \\
\text { girdle } \\
\text { I: Tenaculum }\end{array}$ \\
\hline
\end{tabular}

dorsally by the portio prima and laterally by the protractor and hypaxial muscles (Figures 1A,B, 2 and Supplementary Figures 1, 2). The portio prima takes the form of a rounded chevron originating in a jagged manner from the fascia of the middle third of the iliac ramus and adjacent hypaxial musculature, following the anterior leading edge of the pelvic girdle (Figures 1A,B). This muscle is aligned with the pelvic fin, covering its dorsal surface and inserting into the ceratotrichia and deep dorsal layer. The portio tertia is situated beneath the portio prima and is separated from this muscle by a tendon running along the pelvic girdle ramus (Figure 1B). The portio tertia originates from the ventral surface of the iliac ramus of the pelvic girdle extending ventrally to insert into the deep dorsal layer (Figure 1B). The deep dorsal layer is also located beneath the portio prima, originating from the dorsal surface of the basipterygium, near the acetabulum of the pelvic girdle, extending distally over the fin skeleton and inserts into the dorsal fin radials (Figure 1B). The portio secunda is situated immediately behind and largely covered by the portio prima laterally and posteriorly borders the portio tertia, from which it is separated by a tendon running from the ventral surface of the iliac ramus to the basipterygium (Figures 1A,B). This muscle originates from the fascia of the hypaxial musculature, pelvic girdle, and the cloaca (Figure 1B). The points of insertion for this 


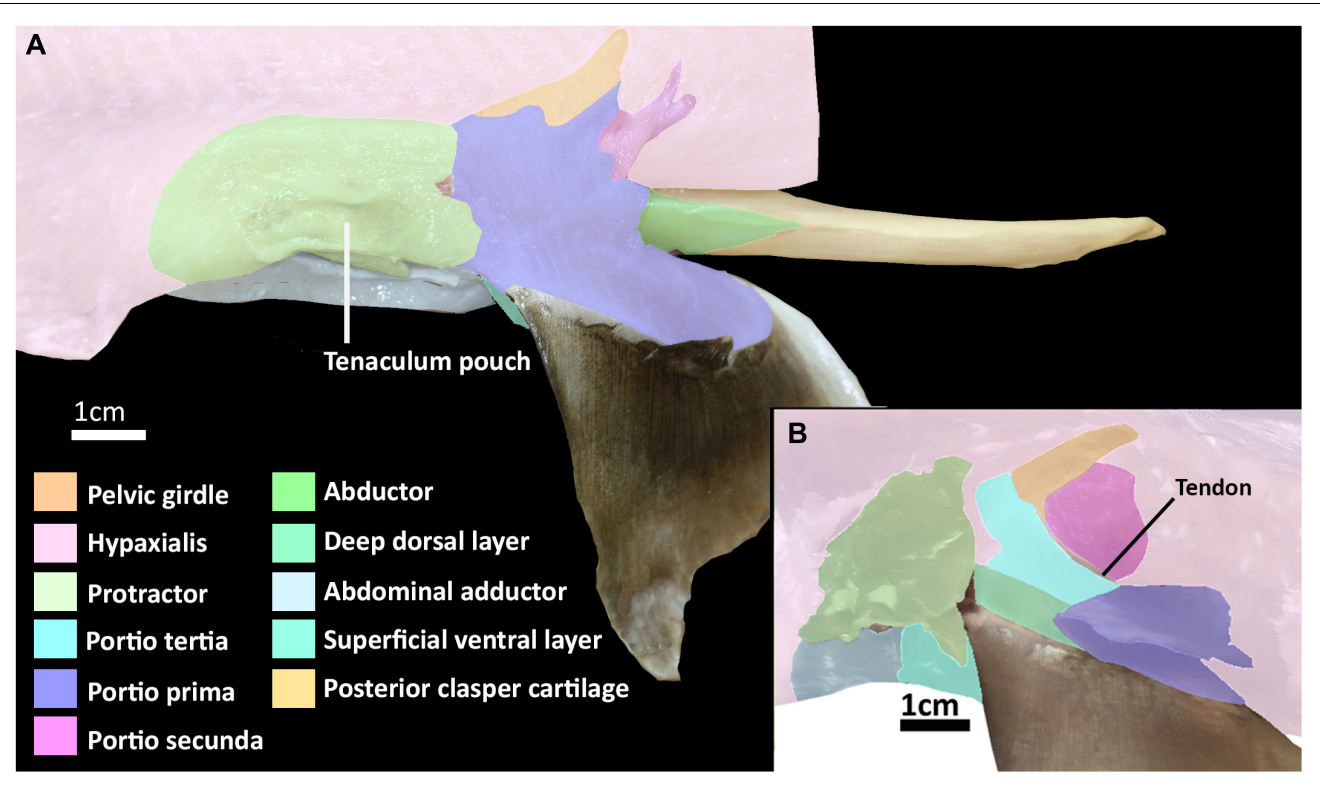

FIGURE 1 | Dissection of the pelvic musculature of the elephant shark (Callorhinchus milii). (A) Lateral view of the superficial dorsal musculature of an adult male, (B) lateral view of the deep dorsal musculature of an adult female with superficial muscles partly removed.

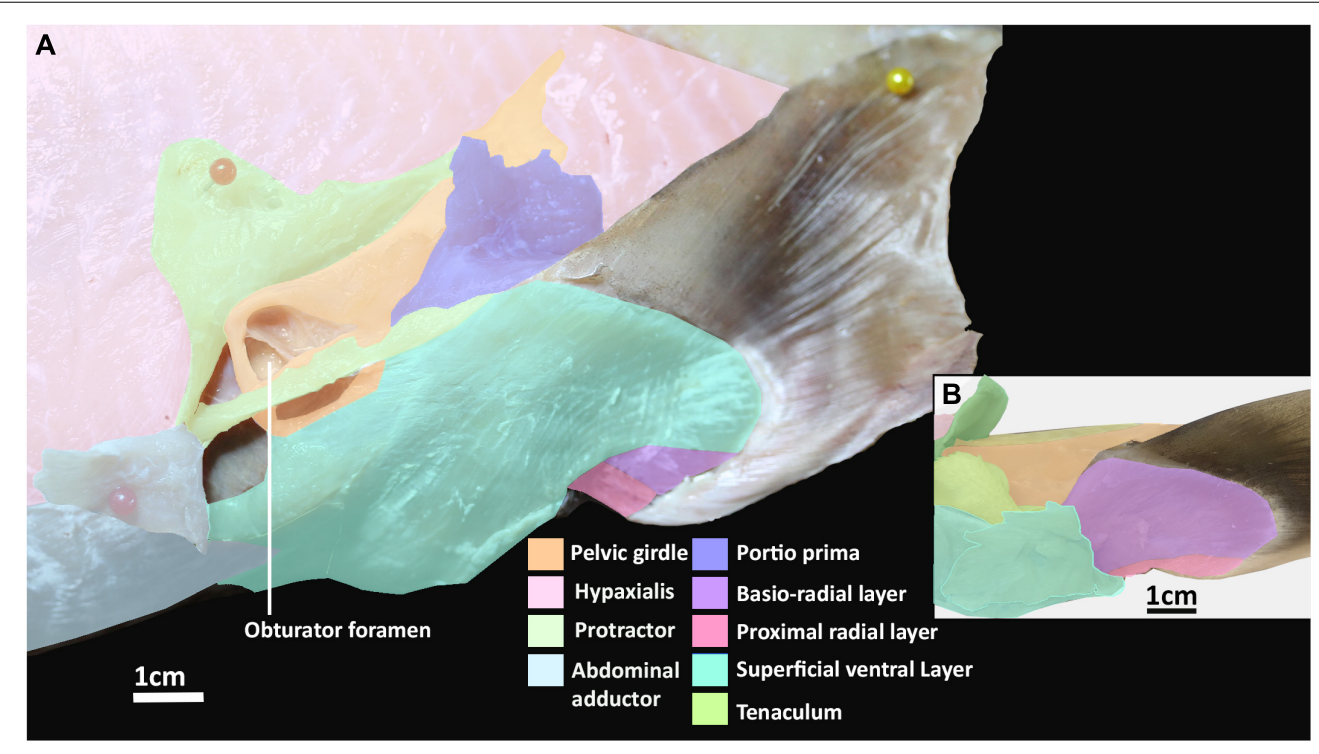

FIGURE 2 | Dissection of the pelvic musculature of an adult elephant shark (Callorhinchus milii). (A) Lateral view of the ventral musculature of a female elephant shark, which has been partially dissected, (B) ventral view of the pelvic fin of an adult male elephant shark.

muscle are sexually dimorphic. In females this muscle inserts into distal surface of the second fin metapterygium (Supplementary Figure 1; sensu Riley et al., 2017) and in males it inserts into the distal surface of the anterior clasper cartilage (Figure 3A).

\section{Lateral Musculature}

The abdominal adductor and protractor form the lateral musculature. The protractor superficially overlies the lower third of the hypaxial musculature, extending along the abdomen with fibers perpendicular to those of the hypaxial musculature and caudally abutting with the portio prima (Figures 1A, 2A). This muscle originates from the fascia of the hypaxial musculature and extends posteriorly forming two points of attachment immediately anterior of the portio prima, giving it the appearance of a stout letter Y rotated $90^{\circ}$ posteriorly (Figure 1). This muscle is sexually dimorphic. In males the protractor has a hole in its lower half from which the pre-pelvic tenaculum protrudes (Figure 2B). In females the pocket is not as prominent. More deeply, this muscle overlays the fascia of the entire anterior third of the pelvic girdle to which it inserts. It also has a 


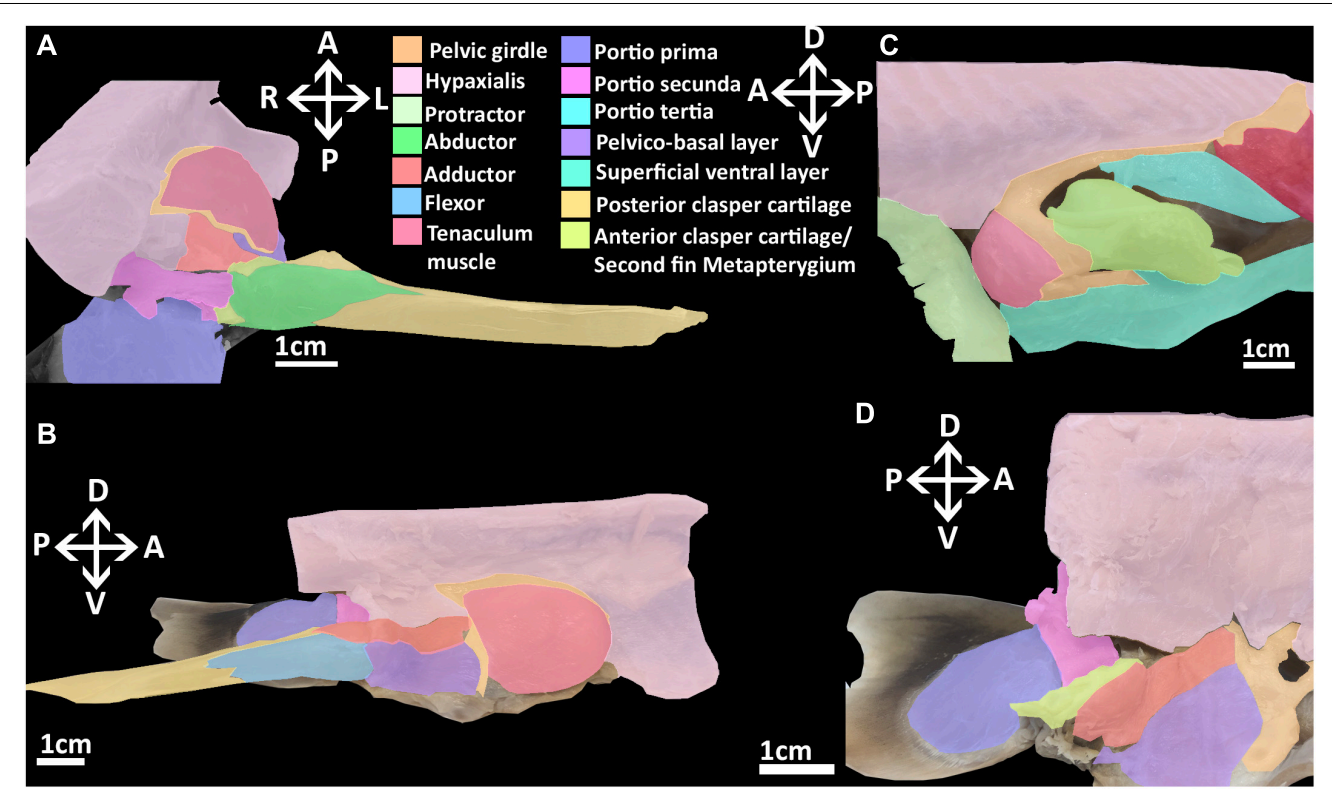

FIGURE 3 | Dissection of the musculature of the pelvic fin and clasper cartilages of the elephant shark (Callorhinchus milii). (A) Posterior view of a dissected male elephant shark, with the pelvic clasper drawn out proximally, (B) medial view of a bisected male elephant shark, showing the internal reproductive musculature, (C) lateral view of a male elephant shark with the protractor and abdominal adductor muscles removed, (D) medial view of a dissected female elephant shark showing the musculature associated with the second fin metapterygium. Anatomical planes and position indicated by lettering: A, Anterior; P, Posterior; D, Dorsal; V, Ventral; R, Right, L, Left.

deeper attachment extending from the ventral surface of the obturator foramen to the basipterygial process (sensu Riley et al., 2017; Figure 2, Supplementary Figure 3). Below the protractor is the abdominal adductor, which takes the form of a very narrow but long isosceles triangle situated along the base of the abdomen over the hypaxial muscles (Figures 1A,B, 2A). The shortest side of this triangle borders with the dorsal end of the superficial ventral layer next to the protractor, while the longer two sides extend anteriorly with protractor extending nearly to the pectoral fin (Figures 1A,B, 2A). This muscle is very superficial, originating from the fascia of the body wall and inserting into the ventral surface of the pelvic girdle near the midline (Figure 2A).

\section{Ventral Musculature}

The ventral musculature is composed of one superficial and two deep components. The superficial ventral layer originates from the ventral surface of the ventral segment of the pelvic girdle where it is most prominent and extends distally to partly cover the ventral surface of the pelvic fin and inserts over most of the basio-radial layer and ceratotrichia anteriorly (Figures 2A,B and Supplementary Figure 3). The basio-radial layer originates from the ventral surface of the basipterygium, near the acetabulum. This muscle extends over most of the surface of the pelvic fin under the superficial ventral layer and inserts into all but the two most proximal fin radials. The proximal radial layer is much smaller relative to these other muscles, originating from the proximal edge of the ventral surface of the basipterygium and anterior clasper cartilage in males and second fin metapterygium in females (Supplementary
Figure 1), near their point of articulation, close to the clasper flexor, extending over the proximal side of the ventral surface of the fin skeleton to insert into the two most proximal fin radials (Figures 2A,B).

\section{Reproductive Musculature}

The reproductive musculature of males includes the clasper abductor, adductor and flexor, pelvico-basal layer. In males, the pelvic clasper consists of two cartilaginous components: the anterior clasper cartilage, articulating to the proximal side of the basipterygium, and the posterior clasper cartilage. The latter is a sheet of folded cartilage forming a rod attached to the distal portion of the anterior clasper cartilage (Didier, 1995). In addition to the portio secunda and proximal radial layer, there are four other muscles that attach to the pelvic claspers: an adductor, an abductor, a flexor, and the pelvico basal layer (Figures 3A,B and Supplementary Figure 4). The adductor originates from the dorsal surface of the ventral segment of the pelvic girdle, abutting with the hypaxial musculature and pelvico-basal layer. The adductor extends posteriorly partially covering the pelvico-basal layer and forming a thick bundle on the dorsal surface, proximal to the central groove, of the anterior clasper cartilage, and spans diagonally to wrap around the central groove of the clasper, inserting into the posterior cartilage (Figures 3A,B). The flexor is situated along the proximal side of the pelvic clasper next to the adductor. It originates from the base of the basipterygium near its articulation with the anterior clasper cartilage and extends posteriorly over a third of the clasper inserting into the posterior cartilage (Figure 3B). The abductor originates from the base of the distal side of 
the anterior clasper cartilage and extends posteriorly over this anterior element to insert laterally into the distal side of the posterior clasper cartilage, wrapping around and covering about a quarter of the clasper's length (Figure 3A). The pelvico-basal layer originates from the dorsal surface of the ventral pelvic segment, below the adductor. This muscle is partially covered by the adductor and extends posteriorly over the girdle to insert into the anterior clasper cartilage below the adductor and in front of the flexor (Figure 3B). The tenaculum muscle, a new term we introduce in this study (see section "Tenaculum Muscle"), originates proximo-laterally from the dorsal surface of the pelvic girdle, specifically the dorsal cartilage of the obturator foramen. This muscle is very broad and covers the proximal side of the obturator foramen. It follows the anterior portion of the pelvic girdle, curving around its most distal point to insert into the base of the pre-pelvic tenaculum. This muscle has no contact with the tenaculum through the obturator foramen, being separated by a fine membrane covering this foramen (Figure 3C).

Females lack pelvic claspers and instead possess a second fin metapterygium. In females, the clasper abductor and flexor muscles are absent. The clasper adductor and pelvico-basal layer are present, but smaller relative to that of males (Figure 3D). These muscles originate from the dorsal surface of the pelvic girdle as they do in males whereas both extend posteriorly to insert into the second fin metapterygium in females. The abductor inserts broadly over the proximal side of the second fin metapterygium covering the attachment of the pelvicobasal layer.

\section{Development of Pelvic Musculature Stage 30 \\ Endoskeleton}

At stage 30, very few elements of the pelvic musculature and skeleton are present or easily discerned (Figure 4). The basipterygium and radials can be identified but they are all peripherally diffuse. The basipterygium is the most clearly discerned skeletal element, having extended distally to form most of the length of the main bar of this structure, but not its width. In contrast to the basipterygium, the fin radials are more diffuse. Only the most proximal radials appear clearly while the more distal elements are more diffuse or absent. None of the radials have any connections with the musculature yet. Rudiments of the pelvic girdle have formed, but these are very diffuse and have not formed across their full span anteriorly or posteriorly.

\section{Dorsal Musculature}

At this stage, a dorsal agglomeration of muscle that bears a resemblance to both the portio prima and deep dorsal layer in its attachments to the skeleton has formed, ranging from the dorsal rudiments of the pelvic girdle to the basipterygium and fin radials (Figure 4). This muscle mass originates from the hypaxial muscle and dorsal rudiments of pelvic girdle and inserts into dorsal surface of the proximal edge of the basipterygium. These are similar to the points of origin of the portio prima and deep dorsal layer, respectively, in the adult. While this muscle has extended over the fin skeleton that has formed so far, it has no contact with the fin radials and instead inserts into the dorsal surface basipterygium, near the proximal fin radials. The portio secunda and portio tertia are absent.

\section{Lateral Musculature}

The protractor and abdominal adductor are both present (Figure 4A), but are very small and thin at this stage. Neither are in contact nor in close proximity with the fin musculature or skeleton. The protractor originates laterally from the hypaxial musculature and at this stage also inserts into the hypaxial musculatures having not yet made contact with the fin skeleton or the rudiments of the pelvic girdle. The abdominal adductor abuts the protractor ventrally, and at this stage also originates from and inserts into the protractor and hypaxial muscles.

\section{Ventral Musculature}

A ventral agglomeration of muscles has formed (Figures 4A,C,D), extending from where the pelvic girdle would be located anteriorly and rudiments of the inter-pelvic band and extends distally near the ventral surface of the basipterygium and fin radials. The location of this agglomeration is reminiscent of both the superficial ventral layer and basioradial layer, but these cannot be distinguished from within this mass at this stage. This mass originates from the inter-pelvic band and inserts along the ventral surface of the basipterygium. The proximal radial layer is absent.

\section{Reproductive Skeleton and Musculature}

The male reproductive and accessory organs and their muscles are absent in this stage.

\section{Stage 32 \\ Endoskeleton}

At this stage, the pelvic endoskeleton and associated musculature are more distinct (Figure 5). The pelvic girdle is well developed, filling most of the area found in the adult, except for its most ventral and most dorsal points and the incomplete obturator foramen, which are diffuse. The fin skeleton has also expanded to a state more similar to that of the adult, with all of its elements being clearly identifiable and only the most distal radials being somewhat diffuse.

\section{Dorsal Musculature}

At this stage, all of the dorsal muscles can be identified. The portio prima is larger than the dorsal agglomeration in stage 30 , extending dorsally to cover approximately two thirds of the iliac process length and posteriorly over the deep dorsal layer. This muscle originates from the middle of the iliac ramus only just inserting into the ceratotrichia in a manner similar to the adult, but less broadly and directly (Figure 5A). Whilst the portio prima extends laterally over part of the hypaxial musculature and pelvic girdle, it does not have the same breadth as that of adults and has not formed its final point of origin over the hypaxial musculature nor the dorsal portion of the iliac ramus. The deep dorsal layer distally covers the fin radials into which it inserts. The portio secunda spans a length similar to that of the adult, but is much thinner overall at this stage. It originates from tissue near the skin, the iliac ramus and cloaca, but is separated from the hypaxial muscle. It becomes thicker ventrally, particularly 


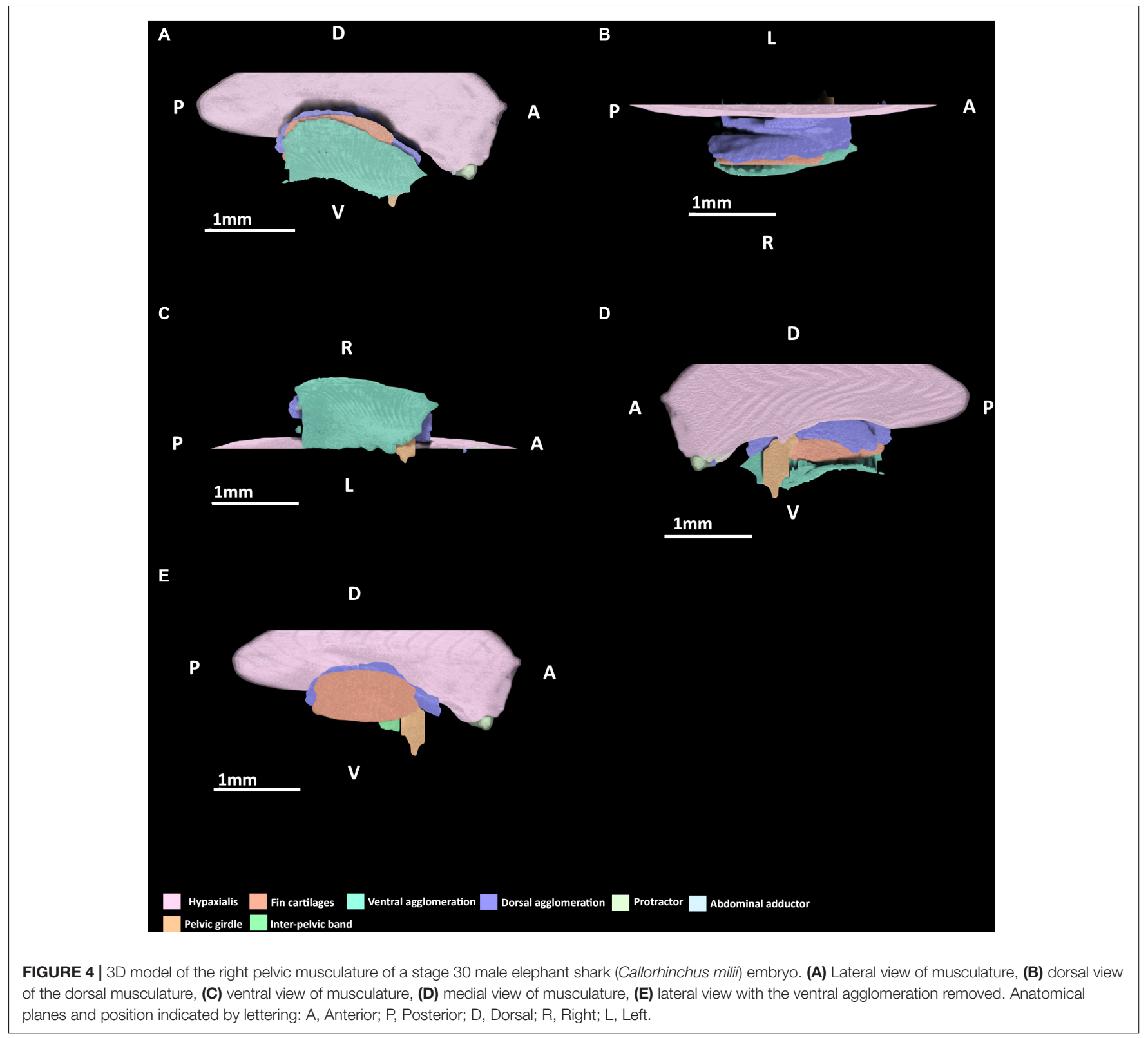

near its point of insertion, but its insertion with the anterior clasper cartilage with very few fibers connecting to this cartilage at this point remains narrow. The portio tertia has the same points of origin and insertion as the adult, originating from the ventral surface of the lower quarter of the iliac ramus of the pelvic girdle and inserting into the proximal end of the deep dorsal layer, immediately posterior of the portio tertia's most ventral point (Figure 5B). However, this muscle is much thinner than that of the adult and does not broadly cover the portions of the girdle it attaches to.

\section{Lateral Musculature}

The protractor extends further posteriorly relative to stage 30, but still has not made contact with the fin skeleton nor the pelvic girdle and so still originates from and inserts into the hypaxial musculature. The abdominal adductor has also extended posteriorly and is in close proximity with the pelvic girdle, specifically into the diffuse ventral arc partially forming the obturator foramen, but has still not yet inserted into this part of the skeleton (Figures 5A,C).

\section{Ventral Musculature}

At this stage, the superficial ventral and basio-radial layers still form a ventral agglomeration and cannot be completely distinguished from one another (Figures 5C,D). This mass originates from the inter-pelvic band, the ventral surface of the anterior segment of the pelvic girdle and the ventral surface of the basipterygium near the acetabulum, which are also the points of origin of the superficial ventral layer and basio-radial layer, respectively, in the adult. This ventral agglomeration spans 


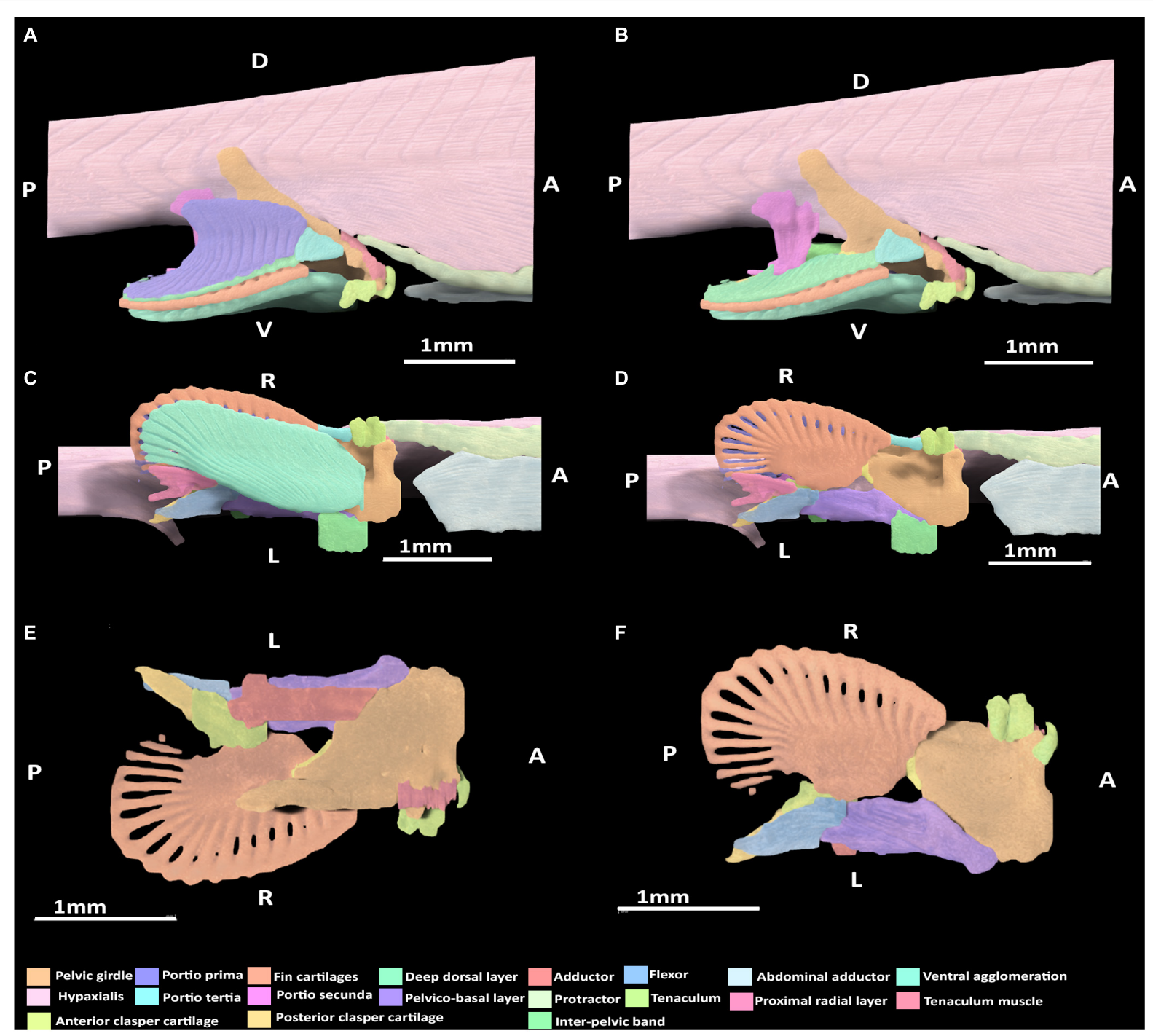

FIGURE 5 | 3D model of the right pelvic musculature of a stage 32 male elephant shark (Callorhinchus milii) embryo. (A) Lateral view of musculature, (B) lateral view with the portio prima removed, (C) ventral view of musculature, (D) ventral view with the superficial ventral layer removed, (E) dorsal view of the reproductive musculature, (F) ventral view of the reproductive musculature. Anatomical planes and position indicated by lettering: A, Anterior; P, Posterior; D, Dorsal; R, Right; L, Left.

most of the ventral surface of the fin skeleton, inserting into the distal portion of the basipterygium and covering, but not connecting with, all but the most proximal fin radials. This muscle is similar in shape to the ventral pelvic musculature, the superficial ventral layer and basio-radial layer, of the adult but does not insert as distally into the fin radials. The proximal radial layer can be identified at this stage and is distinct from the ventral agglomeration. This muscle originates from proximal edge of the basipterygium and anterior clasper cartilage, but whilst it is close proximity with the most proximal fin radials, it has not yet inserted into these cartilages.

\section{Reproductive Skeleton and Musculature}

At this stage, the rudiments of the pelvic clasper cartilages and pre-pelvic tenaculum have begun to form. Despite these structures being diffuse, particularly the posterior clasper cartilage and tenaculum, their associations with the musculature that has formed at this stage can be discerned (Figures 5B,D,E). The tenaculum muscle originates from the dorsal surface of the anterior pelvic girdle, near the developing obturator foramen. This muscle inserts into the base of the tenaculum. The clasper abductor is not present at this stage. The clasper flexor, situated on the proximal side of the pelvic clasper, can be seen to originate ventro-laterally from the basipterygium near its articulation with anterior clasper cartilage, abutting the point of insertion of the pelvico-basal layer. The clasper flexor extends posteriorly to insert proximo-ventrally into the developing posterior clasper cartilage, which it surpasses in length. The clasper adductor has begun to form, being situated on the dorsal surface of the pelvic girdle above the pelvico basal layer. This muscle has not 


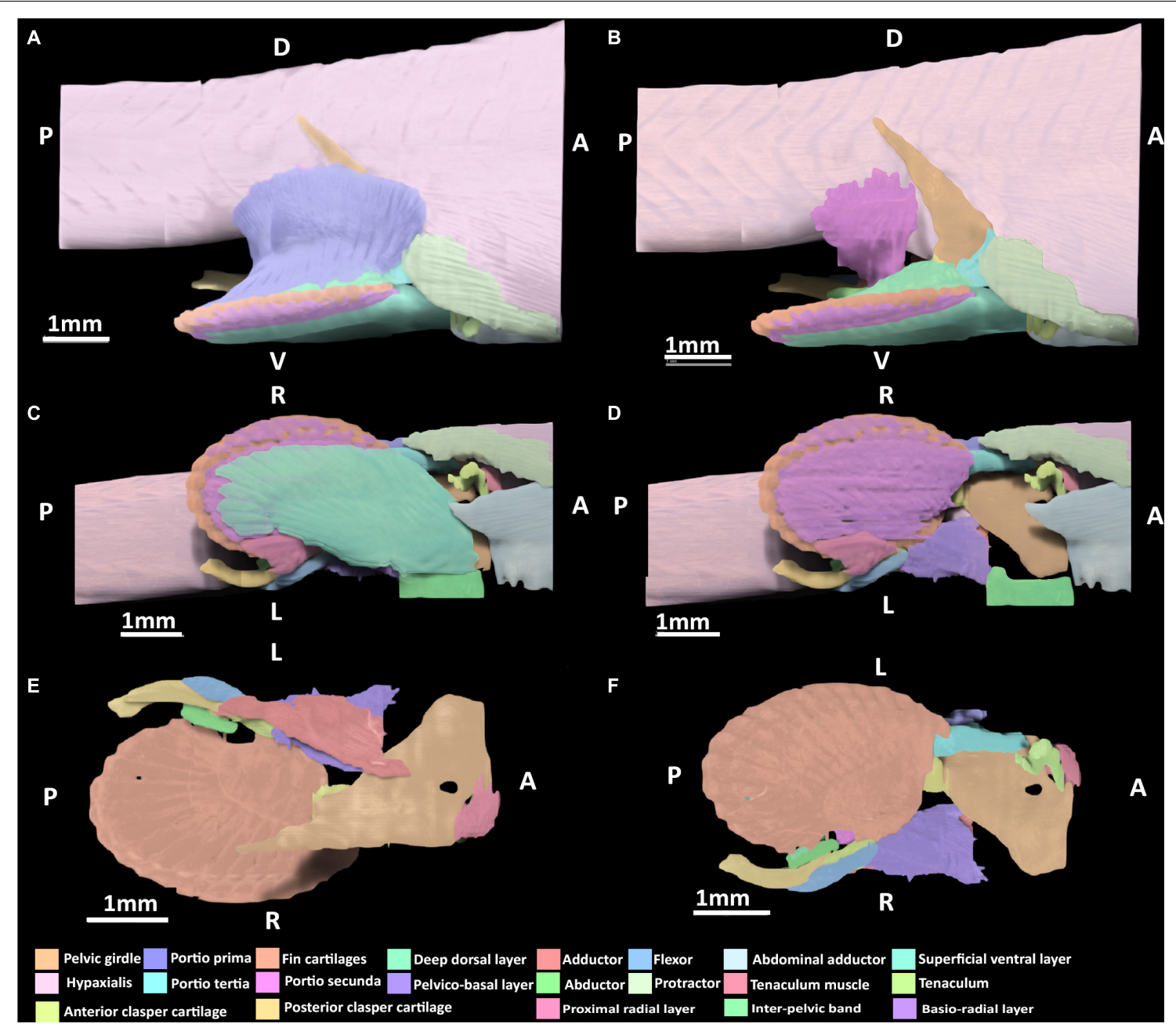

FIGURE 6 | 3D model of the right pelvic musculature of a stage 34 male elephant shark (Callorhinchus milii) embryo. (A) Lateral view of musculature, (B) same view but with the portio prima removed, (C) ventral view of musculature, (D) ventral view with the superficial ventral layer removed, (E) dorsal view of the reproductive musculature, (F) ventral view of the reproductive musculature. Anatomical planes and position indicated by lettering: A, Anterior; P, Posterior; D, Dorsal; R, Right; L, Left.

made contact with the posterior clasper cartilage and instead inserts into the dorsal surface of the anterior clasper cartilage. The pelvico-basal layer originates broadly dorso-laterally from the surface of the ventral segment of the pelvic girdle and the inter-pelvic band, and extends posteriorly to insert laterally and ventrally, into the anterior clasper cartilage, bearing a close resemblance with the adult morphology (Figures 5D,E).

\section{Stage 34 \\ Endoskeleton}

The endoskeleton has become more defined and expanded relative to stage 32 (Figure 6). The fin skeleton in particular is now more complete. Beyond this broadening and expansion there are no other significant change to the endoskeleton.

\section{Dorsal Musculature}

The portio prima has expanded dorsally and laterally, forming its point of origin with the hypaxial musculature and the ramus of the pelvic girdle, very similar to the morphology of an adult (Figure 6A). Compared to stage 32, it has also broadened posteriorly to insert more securely into the deep dorsal layer and more directly into the ceratotrichia as in the adult. The deep dorsal layer, and portio tertia are very similar in terms of their points of origin and insertion to those of stage 32 (Figures 5A,B,D), but are substantially broader and thicker both in terms of size and their respective attachments, bearing a much closer resemblance to the morphology of adults (Figures 6A,B). The portio secunda spans over the hypaxial musculature from which it now originates broadly, in a similar manner to the adult (Figure 6B). This muscle has also become thicker along its length and has broader insertion dorsally into the proximal side of the anterior clasper cartilage.

\section{Lateral Musculature}

The protractor extends further posteriorly compared to stage 32, but has no contact with the fin skeleton and its points of origin 


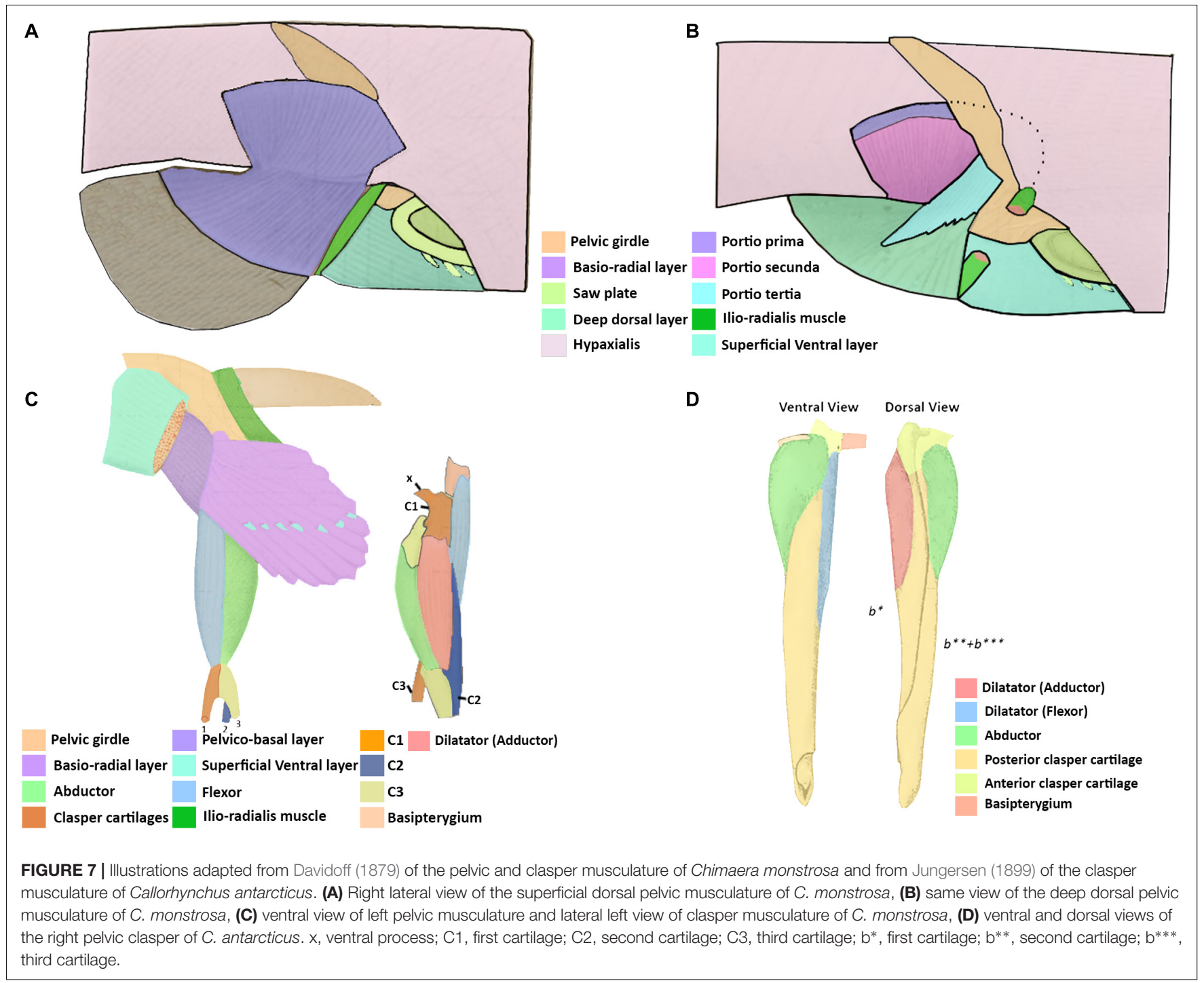

and insertion remain the same as in stage 32 (Figures 6A,C). The abdominal adductor is similar in terms of its points of origin and insertion to those of stage 32 (Figure 5A), but is broader in its span and attachment with the pelvic girdle.

\section{Ventral Musculature}

The superficial ventral layer, basio-radial layer and proximal radial layer are now clearly distinct from each other and their arrangement and span more closely resemble those of the adult (Figures 6C,D). The superficial ventral layer originates from the ventral surface of the anterior pelvic segment and inter-pelvic band, extending posteriorly over the basio-radial layer, into which it inserts distally. The basio-radial layer originates from the ventral surface of the basipterygium near its contact with the pelvic girdle and extends posteriorly over the fin skeleton to insert into the fin radial cartilages. The proximal radial layer has broadened greatly relative to stage 32 and inserts into the most proximal fin radials, and now covers these radials.

\section{Reproductive Skeleton and Musculature}

The skeleton of the pelvic claspers and tenaculum are more developed and distinct relative to stage 32 , however, the posterior regions of the posterior clasper cartilage and tenaculum cartilages are still diffuse. At this stage, all of the reproductive muscles are now present (Figures 6B,D,E). The abductor can be identified, originating from the distal side of the anterior clasper cartilage wrapping around the clasper and extending posteriorly to insert into the posterior clasper cartilage. The clasper adductor now inserts dorso-laterally into the posterior clasper cartilage but does not extend along this cartilage as far as it does in the adult. The clasper flexor is longer posteriorly, extending over almost a third of the posterior clasper cartilage into which it inserts ventro-laterally. Its span across these cartilages is now similar to that of the adult, though it is still shorter posteriorly. The tenaculum muscle has expanded ventrally to more directly attach to the tenaculum cartilages, bearing a closer resemblance to the arrangement of this muscle in the adult, but still much smaller in size. The pelvico-basal layer has thickened relative 
to stage 32 and attaches more broadly to the same points of origin and insertion.

\section{DISCUSSION}

\section{Chimaeroid Pelvic Musculature}

Currently, there are only two published descriptions of the pelvic musculature of extant chimaeroids: both are of members from the family Chimaeridae, the spotted ratfish (Hydrolagus colliei) (Diogo and Ziermann, 2015) and rabbit fish (Chimaera monstrosa) (Davidoff, 1879). These descriptions, separated by 136 years, differ significantly in their descriptions and terminology (Table 2). Below, we compare and contrast these descriptions to propose homologies and establish a better understanding of the pelvic anatomy of extant chimaeroids.

\section{Dorsal Musculature}

The dorsal pelvic musculature of $H$. colliei, C. monstrosa, and C. milii are all composed of superficial and deep portions. However, the points of origin and divisions of these muscles differ (Table 2). The dorsal musculature of $C$. milii corresponds very closely with that of $C$. monstrosa, in that both are divided into four portions and that these have similar points of origin and insertion. In C. monstrosa, the portio prima is described as originating from the "external aponeurosis" extending over the pelvic girdle and adjacent hypaxial muscle, inserting into the ceratotrichia ("secondary fin skeleton") (Davidoff, 1879, p. 477; Figures $7 \mathbf{A}, \mathbf{B}$ ) in the same manner as the portio prima in C. milii, though we also describe the portio prima as inserting into the deep dorsal layer (Figures 1A,B). In both C. milii and C. monstrosa, the portio tertia is located underneath the portio prima, originating from the ventral surface of the iliac ramus of the pelvic girdle and inserting into the deep dorsal layer (tiefe dorsale Schicht). The deep dorsal layer originates laterally from the dorsal surface of the basipterygium and divides posteriorly into bundles that insert into the fin radials (Davidoff, 1879; Figures 1B, 7B). The deep dorsal layer in C. milii also originates from the dorsal surface of the basipterygium near the acetabular articulation to the pelvic girdle. This specific location of the point of origin is not explicitly given in the text of the description of C. monstrosa but is shown in the figures cited (Davidoff, 1879; Figure 7A).

The arrangement of the dorsal pelvic musculature in $\mathrm{H}$. colliei differs slightly from that of C. monstrosa and C. milii in that it is less complex. In $\mathrm{H}$. colliei, the dorsal musculature is divided into three groups: two portions of an adductor and a single levator. The adductor superficialis (superficial bundle) originates from the fascia of the body muscle and extends over the pelvic girdle ramus, and the deep bundle of the adductor originates from the basipterygium extending over the fin skeleton to insert into the fin radials, but the exact point is not described (Diogo and Ziermann, 2015). The points of origin and insertion of the superficial and deep portions of the adductor suggest that they correspond with the portio prima and deep dorsal layer, respectively. However, no muscle resembling the portio tertia is described in H. colliei. As this muscle is situated closely with the portio prima (adductor superficialis) and inserts into the deep dorsal layer (adductor deep bundle) it is possible that the portio tertia has inadvertently been included as a part of one of the other muscles. Alternatively, the portio tertia may not be present in H. colliei. Re-examination is warranted to resolve this issue.

There is more agreement on the muscle known as the portio secunda in C. monstrosa and C. milii and levator 5 in H. colliei. In all of these taxa, this muscle is situated medially behind the more superficial portio prima (adductor superficialis) and posteriorly adjacent to the pelvic girdle (Figures 1A, 7B; Davidoff, 1879; Diogo and Ziermann, 2015). The portio secunda in C. milii (Figures 1, 2) originates from the fascia of the hypaxial musculature, pelvic girdle and cloaca and inserts into the second fin metapterygium in females and the clasper cartilages in males (Figures 1, 3). Likewise, in C. monstrosa, the portio secunda originates from the "external aponeurosis" of the hypaxial musculature and pelvic girdle, and inserts into the most anterior cartilage of the "basal appendage (clasper)" in males and the "basal (second fin metapterygium)" in females (Figures 7A,B; Davidoff, 1879, p. 474). In H. colliei, this muscle is referred to as levator 5 and is described as originating from the fascia of the body muscle and connecting to the basipterygium and medial fin radials. This difference over the points of insertion may arise from a lack of specificity regarding the anatomy of the fin skeleton and the fact that the description of $H$. colliei was based only on female specimens (Diogo and Ziermann, 2015).

\section{Lateral Musculature}

The lateral musculature consists of the protractor and abdominal adductor (Table 3). The protractor described here in C. milii (Figures 1A, 2) shares the same points of origin and insertion, the pelvic girdle and basipterygial process (propterygium), respectively, as those described in H. colliei (Diogo and Ziermann, 2015), suggesting that these muscles are homologous. This muscle is not explicitly identified in the description of C. monstrosa, however, the lateral portions of the hypaxial muscle in the illustrations of the pelvic musculature (Davidoff, 1879, Figure 20, ssv) resemble our description of the protractor and abdominal adductor in C. milii (Figures $\mathbf{1} \mathbf{A}, \mathbf{B}, 2$ ), though the arrangement displayed is not entirely congruent as is in alignment with the pelvic girdle and overlying part of it. This may be because this image was drawn after the removal of the integument. The lateral muscles are not named but are described as follows, "The attachment of the lateral muscles to the pelvis includes only the anterior edge of the ventral, the two cranks and the entire inner surface of the dorsal section" (Davidoff, 1879, p. 474). This description resembles our description some of the attachment points of the protractor and abdominal adductor, but it is too vague to distinguish any specific correlation with our own findings. The other point of difference with regards to the lateral musculature may also a result of omission. No muscle in the descriptions of H. colliei (Diogo and Ziermann, 2015) or C. monstrosa (Davidoff, 1879) appear to correspond with the abdominal adductor in C. milii (Figures 1A,B, 2). As this muscle is small and blends in well with the hypaxial musculature and protractor it may be that the muscle was not identified by other investigators. 


\section{Ventral Musculature}

There are also differences regarding the description of the ventral pelvic musculature among the previous studies and our own findings (Table 4). Again, the ventral musculature of C. milii and C. monstrosa (Davidoff, 1879) are relatively similar, though there is some difference. In C. monstrosa the superficial ventral layer (oberflächliche ventrale Schicht) originates from an aponeurotic band connecting the pelvic girdles and the ventral surface of the ventral portion of the pelvic girdle, extending over the "articulation of the basal with the pelvis" to the fin rays where they divide into bundles and insert into muscle bundles below them, covering the ventral surface of the pelvic fin, except for some posterior lobes (Figures 7C; Davidoff, 1879). This description largely agrees with that of the superficial ventral layer in C. milii, originating from the ventral surface of the pelvic girdle, and an inter-pelvic band in embryos, extending over the acetabulum and basipterygium. We also find that this muscle covers most basio-radial layer in C. milii, completely anteriorly where it inserts into the ceratotrichia and tapering off distally toward the end of the fin, exposing the basio-radial layer into which it also inserts (Figures 2A,B). The basio-radial layer in both $C$. monstrosa and $C$. milii originates from the basipterygium near the acetabulum and extends posteriorly over the ventral surface of the fin skeleton, however, there is some difference in the span of these muscles over the ventral surface of the fin skeleton. In C. monstrosa this muscle is said to cover the entire ventral surface of the pelvic fin, inserting into the radial cartilages (Figures 2, 7C; Davidoff, 1879). In contrast, we find that the basio-radial layer only covers most of the ventral surface of the pelvic fin whereas a distinct proximal radial layer roofs the most proximal regions of the fin skeleton. As the proximal radial layer is subtle in its distinction from the basioradial layer it may have inadvertently included as a part of the basio-radial layer in the description of C. monstrosa, or this may be an interspecific difference. The other main difference with our findings and the description of C. monstrosa, is an extra muscular mass situated between the basio-radial layer and superficial ventral layer, which we have not found in C. milii. In C. monstrosa, this mass is described as "beginning at the medial anterior angle of the fin and running obliquely backwards and laterally," over the fin and connecting with the fascia of the superficial ventral layer and basio-radial layer (Davidoff, 1879, p. 476).

The arrangement of the ventral musculature of the pelvic fin in $H$. colliei is significantly different from that of C. milii and C. monstrosa. In $H$. colliei, this musculature is divided into proximal and distal portions of an abductor (Diogo and Ziermann, 2015). The proximal portion, abductor proximalis, originates from the puboischiac bar (pelvic girdle) and inserts into the basipterygium whereas the distal bundle originates from the basipterygium and extends distally to insert into the ventral surfaces of the radial cartilages (Diogo and Ziermann, 2015). The abductor distalis appears to correspond with the basio-radial layer in C. milii and C. monstrosa as they share the same points of origin and insertion. However, as with C. monstrosa, the proximal radial layer is not described in $H$. colliei and may be included within the abductor distalis (Davidoff, 1879; Diogo and Ziermann, 2015). The proximal bundle of the abductor in $H$. colliei seems to share a common point of origin with the superficial ventral layer of C. milii and C. monstrosa, the puboischiac bar (ventral pelvic segment). However, these muscles do not share the same point of insertion, as the proximal bundle is described as "running. . . to the basipterygium" in H. colliei (Diogo and Ziermann, 2015, p. 523), whilst the superficial ventral layer in both C. milii and C. monstrosa extends over the basipterygium and inserts into the basio-radial layer (Figures 2, 7C; Davidoff, 1879).

\section{Reproductive Musculature}

The pelvic claspers of chimaeroids have been described in several historical and contemporary studies (Davidoff, 1879; Jungersen, 1899; Leigh-Sharpe, 1922, 1926; Didier, 1995), but with limited description of their associated musculature. As far as we are aware there are three descriptions of the clasper musculature in chimaeroids, two of the rabbit fish (Chimaera monstrosa) (Davidoff, 1879; Jungersen, 1899), and one of Callorhynchus antarcticus (sic) (Jungersen, 1899). The clasper skeleton among these genera are notably different. The skeleton of the claspers of C. milii and C. antarcticus, both from the same genus appear to be the same, in that both are composed of two components, a small anterior cartilage attached to the basipterygium and a long folded posterior cartilage connected to the anterior cartilage (Jungersen, 1899; Didier, 1995; Riley et al., 2017). In C. milii, these two cartilages are simply called the anterior and posterior clasper cartilages (Didier, 1995; Riley et al., 2017) and as b1 and the appendix stem in C. antarcticus (Jungersen, 1899), respectively. In contrast, the skeleton of $C$. monstrosa has a branching clasper skeleton composed of three distinct cartilages (Gegenbaur, 1870; Davidoff, 1879; Jungersen, 1899). The first component known as the first cartilage connects with the basipterygium and the other two, the second and third cartilages, branch off from the first cartilage (Davidoff, 1879; C1, C2, C3 in Figure 7C). This suggests that the first cartilage of $C$. monstrosa corresponds with the anterior clasper cartilage as they both join the basipterygium with the posterior clasper cartilage/s (Davidoff, 1879; Didier, 1995). Establishing homologies of the posterior cartilages of C. monstrosa with those of the callorhinchids requires further embryonic studies focusing on the cartilages in these taxa.

All three descriptions of the clasper musculature in chimaeroids, the two historical accounts and our own, agree that the claspers possess three distinct muscles and superficially appear to have a similar arrangement (Figures 3A,B, 7C,D). However, due to the different nature of the skeleton of C. monstrosa, it is not clear how these muscles can be homologized with those of $C$. milii and C. antarcticus. As expected, the description and arrangement of the clasper musculature of $C$. antarcticus are similar to those of C. milii though the nomenclature used differs to each other (Table 5). There are only two notable differences between the two descriptions of the musculature. Firstly, we describe the flexor and adductor as distinct muscles rather than portions of a single dilatator (sic) (Table 5 and Figures 3, 7D; Jungersen, 1899). Secondly, the adductor is much longer and originates from the dorsal surface of the pelvic girdle. Beyond these two details, the 
points of origin and insertion of the muscles in both taxa are the same, though this is not clear at first, as parts of the description of C. antarcticus are not given in a direct manner (Jungersen, 1899). For instance, the compressor (abductor in C. milii) is described thusly, "...the large muscle (S) (compressor) of the glandular bag, which in no respects shows other relations than in Chimaera (monstrosa)," (Jungersen, 1899, p. 75). In turn, the same muscle in C. monstrosa is described as "...M. compressor, arises from the lateral edge of the piece $\beta$ [C3 (Figure 7C)] (see Figure 69), and is inserted on the lateral surface of the piece b1, and on the appendix-stem," (Jungersen, 1899, p. 73). The appendix stem in C. antarcticus corresponds with the posterior clasper cartilage. Similarly, the points of insertion of the portions of the dilatator (sic) are not explicitly stated and are inferred from the figures (see Figure 7D).

The clasper musculature of C. monstrosa comprises three distinct muscles, similar to $C$. milii and $C$. antarcticus with their arrangement. The flexor is situated laterally on the proximal side of the clasper, the adductor is located dorsally above, and the abductor is situated laterally on the distal side. Despite these superficial similarities, there are notable differences in the arrangement of these muscles with the callorhinchids. Whilst the flexor in all of these taxa arises from the basipterygium, this muscle, as well as the adductor and abductor in C. monstrosa insert into the ventral process ( $\mathrm{x}$ in Figure $7 \mathrm{C}$ ), a component of the first cartilage (Davidoff, 1879; Jungersen, 1899). In turn, the adductor and abductor originate from the medial surface of first and second cartilages and the lateral edge of the third cartilage, respectively (Table $\mathbf{5}$ and Figure 7C). The adductor is situated dorsally and is located on the distal side of the clasper rather than proximally, similar to C. milii and C. antarcticus (Figures 3, 7C,D).

An additional muscle called the pelvico-basal layer is also found in both C. milii and C. monstrosa. In C. monstrosa, this muscle is described as originating from the "entire extent of the posterior margin and from part of the dorsal surface of the ventral pelvic segment" and inserting into the process of the pelvic claspers of males and the "basal" (second fin metapterygium) of females (Figure 5B; Davidoff, 1879, p. 475). In the other description of C. monstrosa (Jungersen, 1899), this muscle is considered as a portion of the ventral muscles of the pelvic fin, originating from a tendinous pelvic band and the dorsal surface of the pelvis and inserting into the medial edge of the "basale" (clasper) and its process. This description of the point of origin agrees with what we have observed in C. milii embryos where this muscle arises from an inter-pelvic band and the dorsal surface of the girdle (Table 5). The pelvico-basal layer has not been described in H. colliei (Diogo and Ziermann, 2015) nor in C. antarcticus (Jungersen, 1899). However, as with C. monstrosa it may be that this muscle was inadvertently included in the proximal portion of the abductor, which is also described as originating from the puboischiac bar (Diogo and Ziermann, 2015). This might explain the difference in the point of insertion of this muscle and the superficial ventral layer in C. milii and C. monstrosa. Alternatively, it may be because the muscle was considered out of scope as these authors did not examine the reproductive musculature (Diogo and Ziermann, 2015). It is also possible that as the pelvic musculature of $H$. colliei has only been described in females, it may be that the insertion of the proximal bundle to the "basipterygium" is actually the insertion of the pelvico-basal layer onto the second fin metapterygium. Re-examination of the pelvic musculature in male and female specimens will help clarify this issue.

\section{Tenaculum Muscle}

The muscle associated with the pre-pelvic tenaculum has been described in at least two instances, in C. monstrosa (Davidoff, 1879) and C. antarcticus (Parker, 1886). Both descriptions agree that it arises from the dorsal surface of the pelvic girdle and extends to the pre-pelvic tenaculum (Table 6). This agrees with the arrangement of this muscle that we have found in C. milii (Figure 3). Surprisingly, this muscle has never been named or illustrated and so deserves some attention. In C. monstrosa (Davidoff, 1879), it is described only as the muscle associated with the Saw plate (Sägeblatt) and in C. antarcticus (Parker, 1886) it is simply called the "strong muscle." For clarity, we propose that this muscle should be known as the tenaculum muscle due to its association with the pre-pelvic tenaculum.

\section{Summary of Interspecific Differences}

In terms of the interspecific differences between the pelvic musculatures of the chimaeroids examined here, C. milii and C. monstrosa are more similar to one another than either are to $H$. colliei. The dorsal musculature of C. milii and C. monstrosa is divided in the same groups of muscles, the portio prima, portio tertia, portio secunda, and deep dorsal, and only exhibits minor differences (Table 2). In contrast, the dorsal muscles of $H$. colliei are divided into three components, a superficial and deep adductor and a levator. These muscles appear to correspond well with the portio prima, deep dorsal layer and portio secunda, respectively. Though there is potentially some differences between the insertion of the portio secunda and levator and the portio tertia is not identified in $H$. colliei (Table 2). There may be some differences in the lateral musculature of these taxa, but this is likely due to inadvertent omission in the description of C. monstrosa (Davidoff, 1879) and H. colliei (Diogo and Ziermann, 2015). In C. milii and $H$. colliei the lateral musculature includes a protractor that attaches to the pelvic girdle and part of the fin skeleton. The unidentified muscles are the abdominal adductor in $H$. colliei and C. monstrosa, and protractor in C. monstrosa (but see section "Lateral Musculature"). The ventral musculature of $C$. milii and C. monstrosa is very similar, being composed of a superficial ventral layer and basio-radial layer, with almost the same attachments on the pelvic girdle and fin skeleton, respectively (Table 4). However, C. milii also possess an additional deep muscle along the fin skeleton and clasper cartilage, the proximal radial layer. The ventral musculature of $H$. colliei is also composed of two components, a distal and proximal abductor, however, their points of origin and insertion on the pelvic girdle and fin skeleton differ greatly from those of the superficial ventral layer and basio-radial layer (Table 4).

The reproductive musculature of $C$. milii and $C$. antarcticus are comparable to each other (Table 5) as both possess the same clasper skeletal structure and the arrangement of their 
muscles, the clasper adductor, abductor and flexor, are largely the same. The only difference between the two taxa is that the flexor and adductor are considered bundles of a single muscle in C. anatarcticus. C. monstrosa also has three clasper muscles (Table 5), the flexor, adductor, and abductor. However, due to differences in the clasper skeleton, these are difficult to compare to $C$. milii and C. antarcticus (but see section "Reproductive Musculature"). C. monstrosa and C. milii both have a pelvicobasal layer with essentially the same origin on the pelvic girdle and insertion on the clasper cartilages (Table 5). All three taxa possess a tenaculum muscle originating from the pelvic girdle and inserting into the base of the tenaculum (Table 6).

\section{Comments on Development}

We provide the first detailed descriptions of developmental origins of the pelvic fin muscles in the embryonic series of C. milii. This reveals certain patterns in the growth and development of the muscles. At stage 30, the muscles immediately associated with the fin skeleton, agglomerations of the dorsal (portio prima and deep dorsal layer) and ventral (superficial ventral layer and basioradial layer) muscles, as well as the protractor and abdominal adductor are the first muscles to appear. These muscles are more prominent anteriorly, dorsally and proximally (Figure 4). By stage 32, these muscles have expanded distally, dorsally and posteriorly and the dorsal agglomeration differentiates into the portio prima and deep dorsal layer. At this stage, deeper muscles such as the portio tertia and secunda as well as the muscles associated with reproductive structures (pelvico-basal layer, adductor, flexor, and tenaculum muscle) have formed and are also more prominent dorsally and anteriorly. By stage 34, all of the pelvic and reproductive muscles can be identified and are more prominent relative to stage 32 .

In both $C$. milii and the bamboo shark (Chiloscyllium punctatum), the pelvic fin muscles form from epithelial extensions of the myotome, with epithelial buds migrating ventrally to form the body wall musculature and extending further ventrally into the pelvic fin mesenchyme to form the fin muscles (Cole et al., 2011). The patterns of pelvic fin muscle growth and development observed here may be explained by the trajectory of these epithelial extensions. The antero-posterior development of the musculature observed in the embryos examined would appear to correspond with the suggestion that this is the direction by which these extensions enter the pelvic mesenchyme to form the fin muscle. The development of more superficial elements or their agglomeration with deep components may also suggest that these projections of the epithelium first spread over surface of the fin skeleton before forming the deeper muscles rather than forming the deeper portions first. To date, there has been no examination of the developmental origins of the musculature related to the pre-pelvic tenaculum nor the pelvic claspers in extant chondrichthyans. The tenaculum muscle is in close proximity with the protractor and hypaxial musculature and may likely also result from epithelial extensions. Similarly, the clasper musculature is in close proximity with the musculature of the pelvic fin and pelvico-basal layer, and may also be the result of epithelial extensions. To determine whether these muscles are produced by the same developmental mechanisms requires the examination of origin and arrangement of these structures in more chondrichthyan taxa. The muscle anatomy of reproductive structures has been examined in increasing detail in elasmobranchs in recent studies, which has emphasized the importance of these details in understanding their phylogenetic systematics (de Figueiredo Petean and de Carvalho, 2018; Moreira and de Carvalho, 2018, 2019). There is a notable lack of contemporary information on the musculature of chimaeroid claspers, which is entirely restricted to accounts from over a century ago (Davidoff, 1879; Jungersen, 1899). This indicates a clear need to examine the musculatures in a range of chimaeroid species to verify these historical accounts, refine systematics and determine any insights these may shine on the evolution of vertebrate reproduction.

The prominent size of the superficial musculature in C. milii may have some evolutionary implications for fin muscles. Comparisons of the appendicular musculature between different species of fishes and tetrapods have revealed that superficial muscles are heavier than deep muscles in both limbs of tetrapods whereas deeper muscles are more developed in the fins of fishes (Mansuit and Herrel, 2021). This difference indicates a shift occurred during the fin to limb transition in which tetrapods have experienced a reduction of their deep appendicular muscles and an increase of superficial musculature. This shift is suggested to be an adaptation to the mechanical demands required of terrestrial locomotion, needing more strength to support the body against gravity, as opposed to buoyancy in aquatic habits (Mansuit and Herrel, 2021). Our examination of the musculature indicates that the superficial appendicular musculature is more prominent than the deep musculature in C. milii, at least in terms of surface area. This either suggests that more prominent superficial musculature is plesiomorphic, in which case the tetrapod arrangement is a reversal or that the relative prominence of muscles is driven by biomechanical factors. In order to determine this, differences in the prominence of the superficial and deep appendicular musculature of other extant chondrichthyans, actinopterygian, and sarcopterygian fishes should be investigated and compared to the fossil record.

Currently, the appendicular musculature of fossil vertebrates such as placoderms, chondrichthyans and osteichthyans are not well known. Soft tissues do not normally fossilize, however, in certain specimens, such as those from the Gogo formation, soft tissues, including muscles, or muscle attachment scars, are preserved. These specimens can be used to investigate and partially reconstruct the arrangement of the musculature of fossil taxa (Trinajstic et al., 2007, 2013, 2015). This is best demonstrated by the detailed reconstruction of the head, neck and abdominal muscles in arthrodire placoderms from preserved tissues. Muscle scars are present on the pelvic girdle and fin endoskeleton of placoderms from the Gogo formation (pers obs) but have not been described. Chondrichthyan musculatures were thought to be very simple, which appeared incongruent with the complexity of placoderm musculatures found in the Gogo arthrodires (Trinajstic et al., 2013). Here, we have shown that chondrichthyan musculatures are more complex than currently thought providing important details to guide interpretation of fossil musculatures (Lund and Grogan, 1997). 
Fossil specimens with preserved musculature or muscle scars should be examined to better understand the arrangement of the appendicular musculature and determine the evolutionary shifts that have occurred in the early evolution of limbs in gnathostomes. Some fossil specimens also possess preserved reproductive claspers (Trinajstic et al., 2015). Studies on these structures and any possible muscle reconstructions compared with those of extant chondrichthyans will help better understand the development and evolution of vertebrate reproduction.

\section{Comparative Development of Pelvic Musculature}

To date, only one ontogenetic study of the pelvic muscles in chondrichthyan has been conducted (Ziermann et al., 2017). Ziermann et al. (2017) describe the morphology and development of the cephalic, pectoral and pelvic muscles in the catshark (Scyliorhinus canicula) from stages 26 to 33 using a combination of scanning electron microscopy (SEM), traditional histology and whole mount immunostaining. The staging table for C. milii is based on that of $S$. canicula, making their respective stages approximately equivalent (Ballard et al., 1993; Didier et al., 1998), and thereby making the comparison of their development fairly straightforward.

In S. canicula, muscle projections are thought to ventrally extend to the base of the pelvic fins between stages 27 and 28 but no specific muscles can be identified at these stages. By stage 30 , the ventral muscles are present as an undivided abductor and the dorsal muscles as the adductor superficialis (Ziermann et al., 2017). In C. milii, by stage 30, agglomerations of the dorsal (portio prima and deep dorsal layer) and ventral (superficial ventral layer and basio-radial layer) muscles have formed (Figures $4 \mathrm{~A}, \mathrm{C}, \mathrm{D}$ ). In terms of morphology and level of development, the two species are similar at this stage. However, in our nano-CT data, we distinguish two muscles, respectively, within both the ventral and dorsal agglomerations through their attachment points on the rudimentary skeleton. Through this nano-CT imaging method we can identify the deep dorsal layer (adductor profundus) within the dorsal agglomeration which was not identified in S. canicula, possibly because of the limitations of the techniques used. Through the use of nano-CT imaging, we are also able to identify the lateral musculature, the protractor and abdominal adductor, in C. milii at stage 30 (Figure $\mathbf{4 A}$ ), which could not be identified in S. canicula at this stage. By stage 32 , most components of the pelvic musculature in C. milii can be identified (Figure 5). The dorsal muscles can be distinguished from one another, and most of the reproductive musculature can be identified, though, apart from the proximal radial layer, the ventral muscles still consist of an agglomeration. The ventral musculature of $S$. canicula at stage 32 and 33 remains undifferentiated and neither the deep dorsal musculature nor the lateral muscles are identified at these stages, with stage 33 being the last stage examined (Ziermann et al., 2017). It is not clear when the deep portion of the adductor or retractor/levator5 is formed in S. canicula. These discrepancies in the formation of the musculature may be derived from interspecific differences in the rate of development. Alternatively, these may arise from differences in methodology.
The use of nano-CT imaging has allowed us to identify and visualize early differentiations of muscles in $3 \mathrm{D}$, which are difficult to achieve with traditional histology or whole mount immunostaining where structures may obscure one another and prevent a complete analysis of the anatomy. This highlights that the CT imaging and $3 \mathrm{D}$ visualization techniques in tandem with traditional methods will help ensure a comprehensive study of the anatomies.

To date, there are no studies on the development of the musculature of the pelvic claspers or tenaculum in other holocephalans or other cartilaginous fish. The examination of the morphology and development of these structures in other chondrichthyans as well as fossil taxa such as placoderms are required to determine any morphological similarities or homologies between the musculature of claspers among these taxa and to further understand the evolution of vertebrate reproduction.

\section{CONCLUSION}

Our findings indicate that the pelvic musculature of extant chimaeroids is more complex than suggested by contemporary and historical descriptions (Davidoff, 1879; Diogo and Ziermann, 2015), but agree more with the complexity described in the historical literature (Davidoff, 1879). The revised adult anatomy is essential for interpreting embryonic development. Our work has been greatly aided through reading the historical literature written by the original comparative anatomists and embryologists, much of which appears to have largely been forgotten or overlooked. Such works are treasure stores of much needed anatomical and embryological data that can inform current comparative analyses of different outgroups to bracket evolutionary transitions (Boisvert et al., 2013; Dearden et al., 2021). This will help form hypotheses on evolutionary processes that have shaped the vertebrate skeleton, which can be tested with fossil data that can possess well preserved soft tissues for analyses of the musculature (Trinajstic et al., 2013, 2018). In particular, the holocephalian pelvic musculature described here compares well to the complexity inferred for some Palaeozoic jawless fishes. These anatomies imply an equally complex origin of the pelvis and its musculature. The other great aid to this work has been the use of CT imaging and 3D visualization, which has enabled us to identify the early development of the pelvic musculature and pick apart some of the subtle complexities of the anatomy that are difficult to identify solely through analog dissection. This synthesis, combining the knowledge from the historic literature and analog dissection with modern CT imaging and digital dissections, can shed light on the complexity of anatomy, morphological transformations and their underlying mechanisms underpinning major evolutionary events.

\section{DATA AVAILABILITY STATEMENT}

The original contributions presented in the study are included in the article/Supplementary Material, further inquiries can be directed to the corresponding author/s. 


\section{ETHICS STATEMENT}

The animal study was reviewed and approved by the Monash University Animal Ethics Committee (Permit: MAS/ARMI/2010/01).

\section{AUTHOR CONTRIBUTIONS}

$\mathrm{CB}$ conceived this project and acquired the specimens used. HL and RT conducted the nano-CT imaging. JP and CT segmented and modeled the nano-CT data. JP and $\mathrm{CB}$ performed the dissections and analysis of the gross anatomy and interpreted the data, and wrote the manuscript. All authors reviewed the manuscript.

\section{FUNDING}

This work was supported by the Curtin Research fellowship: CB, Australian Government Research Training Program Scholarship (AGRTP): JP, ARC discovery grant 1096002. The nano-CT instrument was funded by Canadian Foundation of Innovation project 33122 to the infrastructure of the Integrated Quantitative Biology Initiative (IQBI).

\section{REFERENCES}

Balfour, F. M. (1878). A Monograph on The Development of Elasmobranch Fishes. Basingstoke: Macmillan. doi: 10.5962/bhl.title.7847

Balfour, F. M. (1881). "On the development of the skeleton of the paired fins of elasmobranchii, considered in relation to its bearings on the nature of the limbs of the vertebrata," in Proceedings of the Zoological Society of London (Hoboken, NJ: Wiley Online Library), 656-670. doi: 10.1111/j.1096-3642.1881.tb01323.x

Ballard, W. W., Mellinger, J., and Lechenault, H. (1993). A series of normal stages for development of Scyliorhinus canicula, the lesser spotted dogfish (Chondrichthyes: Scyliorhinidae). J. Exp. Zool. 267, 318-336. doi: 10.1002/jez. 1402670309

Boisvert, C. A., Joss, J. M., and Ahlberg, P. E. (2013). Comparative pelvic development of the axolotl (Ambystoma mexicanum) and the Australian lungfish (Neoceratodus forsteri): conservation and innovation across the fishtetrapod transition. Evodevo 4, 1-19. doi: 10.1186/2041-9139-4-3

Boisvert, C. A., Martins, C. L., Edmunds, A. G., Cocks, J., and Currie, P. (2015). Capture, transport, and husbandry of elephant sharks (Callorhinchus milii) adults, eggs, and hatchlings for research and display. Zoo Biol. 34, 94-98. doi: $10.1002 /$ zoo. 21183

Braus, H. (1898). Ueber die innervation der paarigen extremitäten bei selachiern, holocephalen und dipnoern. Jena. Zeitschr. Naturwiss. 31, 239-486.

Braus, H. (1899). Beiträge zur entwicklung der muskulatur und des peripheren nervensystems der selachier. Morphol. Jahrbuch 27, 501-629.

Brazeau, M. D., and Friedman, M. (2015). The origin and early phylogenetic history of jawed vertebrates. Nature 520, 490-497. doi: 10.1038/nature14438

Cole, N. J., and Currie, P. D. (2007). Insights from sharks: evolutionary and developmental models of fin development. Dev. Dyn. 236, 2421-2431. doi: 10.1002/dvdy. 21268

Cole, N. J., Hall, T. E., Don, E. K., Berger, S., Boisvert, C. A., Neyt, C., et al. (2011). Development and evolution of the muscles of the pelvic fin. PLoS Biol. 9:e1001168. doi: 10.1371/journal.pbio.1001168

Coolen, M., Menuet, A., Chassoux, D., Compagnucci, C., Henry, S., Lévèque, L., et al. (2008). The dogfish Scyliorhinus canicula: a reference in jawed vertebrates. Cold Spring Harb. Protoc. 2008:emo111. doi: 10.1101/pdb.emo111

\section{ACKNOWLEDGMENTS}

We would like to thank Assoc. Prof. Andrew Woods and the Curtin Hub for Immersive Visualisation and eResearch (HIVE) for their assistance and patience with the modeling of the nanoCT data. We would also like to thank Peter Currie, Carmen Sontaag, and Wendy Chua for elephant shark support. We thank Katharine Criswell and Richard Dearden for their feedback in improving the manuscript.

\section{SUPPLEMENTARY MATERIAL}

The Supplementary Material for this article can be found online at: https://www.frontiersin.org/articles/10.3389/fevo.2021. 812561/full\#supplementary-material

Supplementary Figure 1 | Illustration of the pelvic skeleton of a female elephant shark (Callorhinchus milii).

Supplementary Figure 2 | Photographed images of dissected elephant shark pelvic musculature (Callorhinchus milii) from Figure 1 without color overlays.

Supplementary Figure 3 | Photographed images of dissected elephant shark ventral pelvic musculature (Callorhinchus milii) from Figure 2 without color overlays.

Supplementary Figure 4 | Photographed images of dissected elephant shark reproductive musculature (Callorhinchus milii) from Figure 3 without color overlays.

Davidoff, M. (1879). Beitrage zur vergleichenden anatomie der hinteren gliedmassen der fische. Morphol. Jahrbuch 5, 450-520.

de Figueiredo Petean, F., and de Carvalho, M. R. (2018). Comparative morphology and systematics of the cookiecutter sharks, genus Isistius Gill (1864)(Chondrichthyes: Squaliformes: Dalatiidae). PLoS One 13:e0201913. doi: 10.1371/journal.pone.0201913

Dearden, R. P., Mansuit, R., Cuckovic, A., Herrel, A., Didier, D., Tafforeau, P., et al. (2021). The morphology and evolution of chondrichthyan cranial muscles: a digital dissection of the elephantfish Callorhinchus milii and the catshark Scyliorhinus canicula. J. Anatomy 238, 1082-1105. doi: 10.1111/joa.13362

Didier, D. A. (1995). Phylogenetic Systematics of Extant Chimaeroid Fishes (Holocephali, Chimaeroidei): American Museum Novitates (3119). New York, NY: American Museum of Natural History, 1-88.

Didier, D. A., LeClair, E. E., and Vanbuskirk, D. R. (1998). Embryonic staging and external features of development of the chimaeroid fish, Callorhinchus milii (Holocephali, Callorhinchidae). J. Morphol. 236, 25-47. doi: 10.1002/(SICI) 1097-4687(199804)236:1<25::AID-JMOR2>3.0.CO;2-N

Diogo, R. (2020). Cranial or postcranial-dual origin of the pectoral appendage of vertebrates combining the fin-fold and gill-arch theories? Dev. Dyn. 249, 1182-1200. doi: $10.1002 /$ dvdy.192

Diogo, R., and Molnar, J. (2014). Comparative anatomy, evolution, and homologies of tetrapod hindlimb muscles, comparison with forelimb muscles, and deconstruction of the forelimb-hindlimb serial homology hypothesis. Anat. Rec. 297, 1047-1075. doi: 10.1002/ar.22919

Diogo, R., and Ziermann, J. (2015). Muscles of chondrichthyan paired appendages: comparison with Osteichthyans, deconstruction of the fore-hindlimb serial homology dogma, and new insights on the evolution of the vertebrate neck. Anat. Rec. 298, 513-530. doi: 10.1002/ar.23047

Dohrn, A. (1884). Die paarigen und unpaaren flossen der selachier. Studien zur urgeschichte des wirbeltierkörpers. VI. mitteilungen der zool. Station Neapel Bd $5: 1884$.

Edgeworth, F. (1911). Memoirs: on the morphology of the cranial muscles in some vertebrates. J. Cell Sci. 2, 167-316. doi: 10.1242/jcs.s2-56.222.167

Edgeworth, F. H. (1935). The Cranial Muscles Of Vertebrates. Cambridge: Cambridge University Press. 
Ehrlich, H. (2010). Biological Materials of Marine Origin. Dordrecht: Springer. doi: 10.1007/978-90-481-9130-7

Freitas, R., Gómez-Skarmeta, J. L., and Rodrigues, P. N. (2014). New frontiers in the evolution of fin development. J. Exp. Zool. Part B 322, 540-552. doi: 10.1002/jez.b.22563

Gegenbaur, C. (1870). Ueber die modificationen des skeletts der hintergliedmassen bei den mannchen der selachier und chimaren. Jena. Z. Naturwiss. 5:448.

Goodrich, E. S. (1906). Memoirs: notes on the development, structure, and origin of the median and paired fins of fish. J. Cell Sci. 2, 333-376. doi: 10.1242/jcs.s250.198 .333

Inoue, J. G., Miya, M., Lam, K., Tay, B.-H., Danks, J. A., Bell, J., et al. (2010). Evolutionary origin and phylogeny of the modern holocephalans (Chondrichthyes: Chimaeriformes): a mitogenomic perspective. Mol. Biol. Evol. 27, 2576-2586. doi: 10.1093/molbev/msq147

Jungersen, H. F. E. (1899). On The Appendices Genitales In The Greenland Shark, Somniosus Microcephalus (Bl. Schn.), And Other Selachians. Copenhagen: Bianco Luno (F. Dreyer). doi: 10.5962/bhl.title.14334

Larouche, O., Zelditch, M. L., and Cloutier, R. (2017). Fin modules: an evolutionary perspective on appendage disparity in basal vertebrates. BMC Biol. 15:32. doi: 10.1186/s12915-017-0370-x

Leigh-Sharpe, W. H. (1922). The comparative morphology of the secondary sexual characters of Holocephali and elasmobranch fishes. The claspers, clasper siphons, and clasper glands. J. Morphol. 36, 199-220. doi: 10.1002/jmor. 1050360204

Leigh-Sharpe, W. H. (1926). The comparative morphology of the secondary sexual characters of elasmobranch fishes. The claspers, clasper siphons, and clasper glands. Memoir X. J. Morphol. 42, 335-348. doi: 10.1002/jmor.1050420111

Lund, R., and Grogan, E. D. (1997). Relationships of the chimaeriformes and the basal radiation of the chondrichthyes. Rev. Fish Biol. Fish. 7, 65-123. doi: 10.1023/A:1018471324332

Maisey, J. (2012). What is an 'elasmobranch'? The impact of palaeontology in understanding elasmobranch phylogeny and evolution. J. Fish Biol. 80, 918-951. doi: 10.1111/j.1095-8649.2012.03245.x

Mansuit, R., and Herrel, A. (2021). The evolution of appendicular muscles during the fin-to-limb transition: possible insights through studies of soft tissues, a perspective. Front. Ecol. Evol. 9:508. doi: 10.3389/fevo.2021.702576

Mollier, S. (1892). Zur entwickelung der selachierextremitaeten. Anat. Anzeiger 7 , 351-365.

Moreira, R. A., and de Carvalho, M. R. (2018). Morphology of the clasper musculature in rays (Chondrichthyes; Elasmobranchii: Batoidea), with comments on their phylogenetic interrelationships. J. Morphol. 279, 1827-1839. doi: 10.1002/jmor.20904

Moreira, R. A., and de Carvalho, M. R. (2019). Clasper morphology of the japanese sawshark, Pristiophorus japonicus Günther, 1870 (Chondrichthyes: Elasmobranchii). Anat. Rec. 302, 1666-1670. doi: 10.1002/ar.24082

Neyt, C., Jagla, K., Thisse, C., Thisse, B., Haines, L., and Currie, P. (2000). Evolutionary origins of vertebrate appendicular muscle. Nature 408, 82-86. doi: $10.1038 / 35040549$

Parker, T. (1886). On the claspers of Callorhynchus. Nat. Lond. 34:635. doi: 10.1038/ $034635 \mathrm{a} 0$
Riley, C., Cloutier, R., and Grogan, E. D. (2017). Similarity of morphological composition and developmental patterning in paired fins of the elephant shark. Sci. Rep. 7, 1-10. doi: 10.1038/s41598-017-10538-0

Siomava, N., Fuentes, J. S., and Diogo, R. (2020). Deconstructing the long-standing a priori assumption that serial homology generally involves ancestral similarity followed by anatomical divergence. J. Morphol. 281, 1110-1132. doi: 10.1002/ jmor. 21236

Tanaka, M., Münsterberg, A., Anderson, W. G., Prescott, A. R., Hazon, N., and Tickle, C. (2002). Fin development in a cartilaginous fish and the origin of vertebrate limbs. Nature 416, 527-531. doi: 10.1038/416527a

Trinajstic, K., Boisvert, C., Long, J. A., and Johanson, Z. (2018). "Evolution of vertebrate reproduction," in Evolution and Development of Fishes, eds C. Underwood, M. Richter, and Z. Johanson (Cambridge: Cambridge University Press), 207-226. doi: 10.1017/9781316832172.013

Trinajstic, K., Boisvert, C., Long, J., Maksimenko, A., and Johanson, Z. (2015). Pelvic and reproductive structures in placoderms (stem gnathostomes). Biol. Rev. 90, 467-501. doi: 10.1111/brv.12118

Trinajstic, K., Marshall, C., Long, J., and Bifield, K. (2007). Exceptional preservation of nerve and muscle tissues in Late Devonian placoderm fish and their evolutionary implications. Biol. Lett. 3, 197-200. doi: 10.1098/rsbl.2006.0604

Trinajstic, K., Sanchez, S., Dupret, V., Tafforeau, P., Long, J., Young, G., et al. (2013). Fossil musculature of the most primitive jawed vertebrates. Science 341, 160-164. doi: 10.1126/science. 1237275

Venkatesh, B., Lee, A. P., Ravi, V., Maurya, A. K., Lian, M. M., Swann, J. B., et al. (2014). Elephant shark genome provides unique insights into gnathostome evolution. Nature 505:174. doi: 10.1038/nature12826

Wilhelm, B. C., Du, T. Y., Standen, E. M., and Larsson, H. C. (2015). Polypterus and the evolution of fish pectoral musculature. J. Anat. 226, 511-522. doi: 10.1111/joa.12302

Ziermann, J. M., Freitas, R., and Diogo, R. (2017). Muscle development in the shark Scyliorhinus canicula: implications for the evolution of the gnathostome head and paired appendage musculature. Front. Zool. 14:31. doi: 10.1186/s12983017-0216-y

Conflict of Interest: The authors declare that the research was conducted in the absence of any commercial or financial relationships that could be construed as a potential conflict of interest.

Publisher's Note: All claims expressed in this article are solely those of the authors and do not necessarily represent those of their affiliated organizations, or those of the publisher, the editors and the reviewers. Any product that may be evaluated in this article, or claim that may be made by its manufacturer, is not guaranteed or endorsed by the publisher.

Copyright (C) 2022 Pears, Tillett, Tahara, Larsson and Boisvert. This is an open-access article distributed under the terms of the Creative Commons Attribution License (CC BY). The use, distribution or reproduction in other forums is permitted, provided the original author(s) and the copyright owner(s) are credited and that the original publication in this journal is cited, in accordance with accepted academic practice. No use, distribution or reproduction is permitted which does not comply with these terms. 